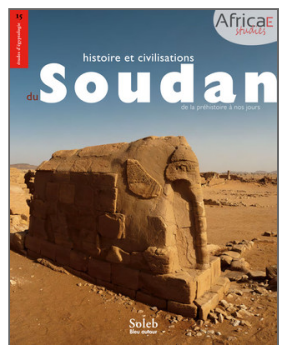

Olivier Cabon (dir.)

Histoire et civilisation du Soudan

De la préhistoire à nos jours

\title{
Le royaume de Méroé, un monde urbain
}

\section{Marc Maillot}

DOI : 10.4000/books.africae. 2857

Éditeur : Africae, Soleb, Bleu autour

Lieu d'édition : Paris, Khartoum

Année d'édition : 2017

Date de mise en ligne : 17 janvier 2022

Collection : Africae Studies

EAN électronique : 9782493207074

\section{OpenEdition}

\section{Books}

http://books.openedition.org

\section{Référence électronique}

MAILLOT, Marc. Le royaume de Méroé, un monde urbain In : Histoire et civilisation du Soudan : De la préhistoire à nos jours [en ligne]. Paris, Khartoum : Africae, 2017 (généré le 28 janvier 2022). Disponible sur Internet : <http://books.openedition.org/africae/2857>. ISBN : 9782493207074. DOI : https:// doi.org/10.4000/books.africae.2857. 


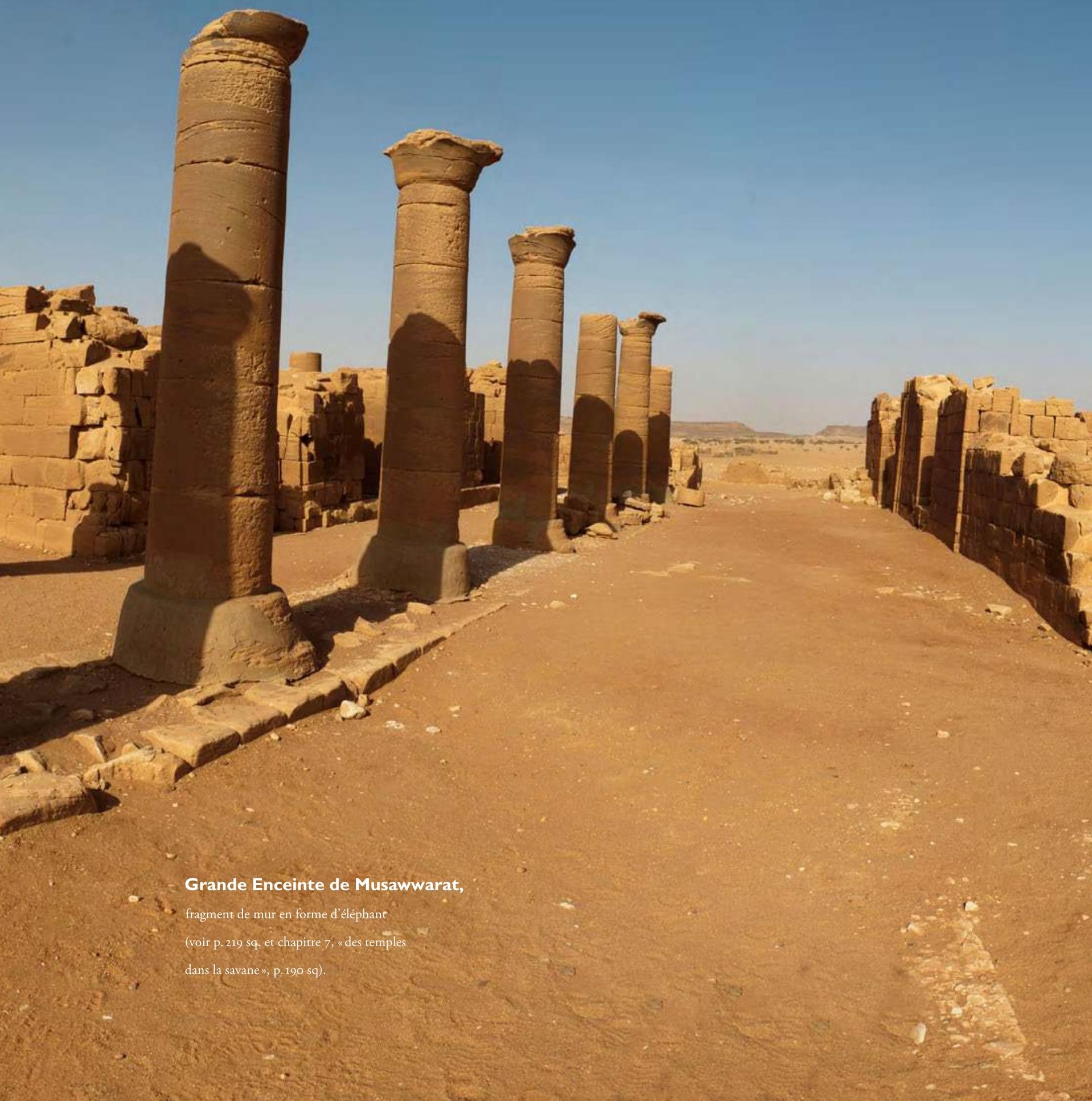




\section{le royaume de Méroé, un monde urbain}

Marc Maillot

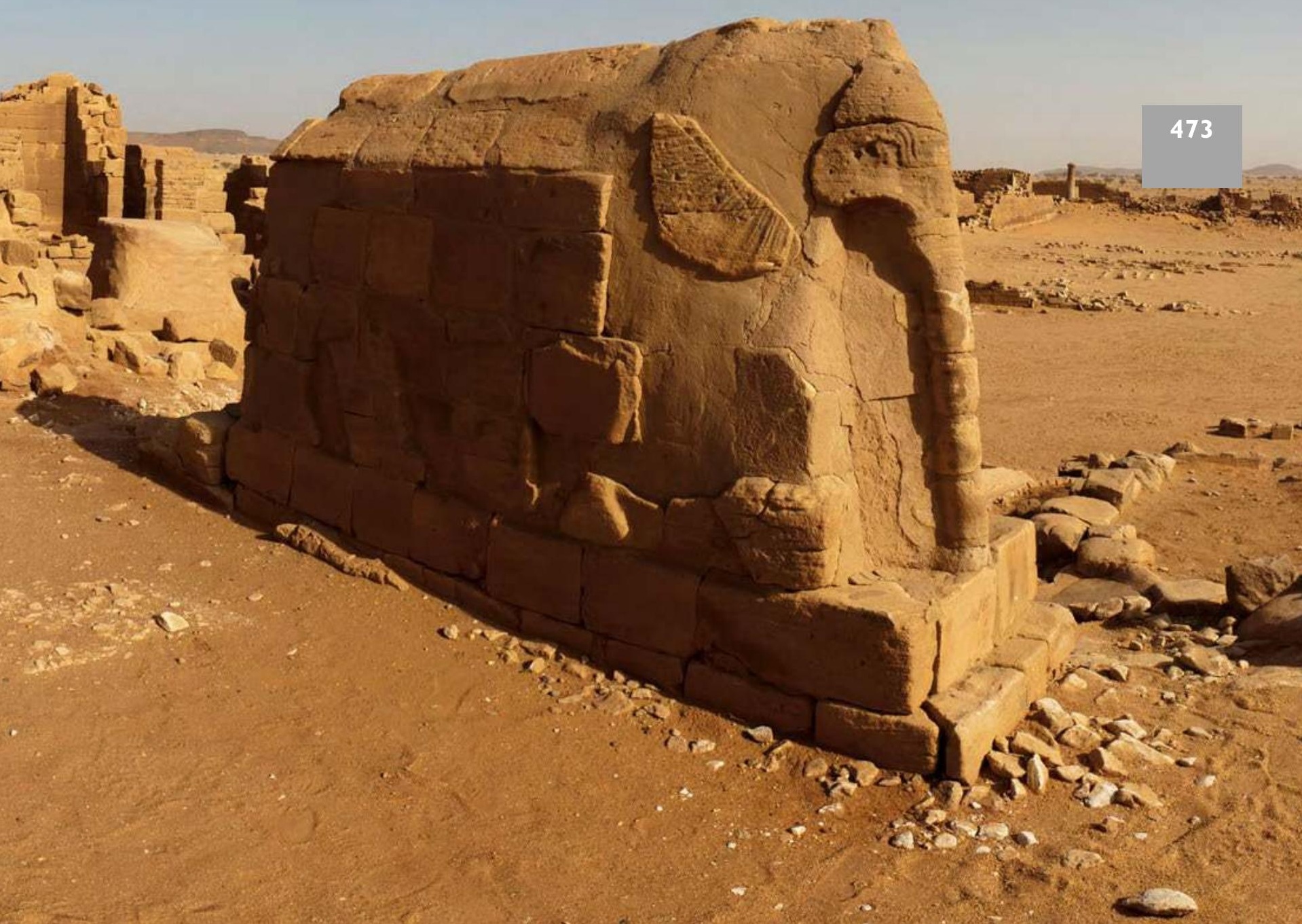




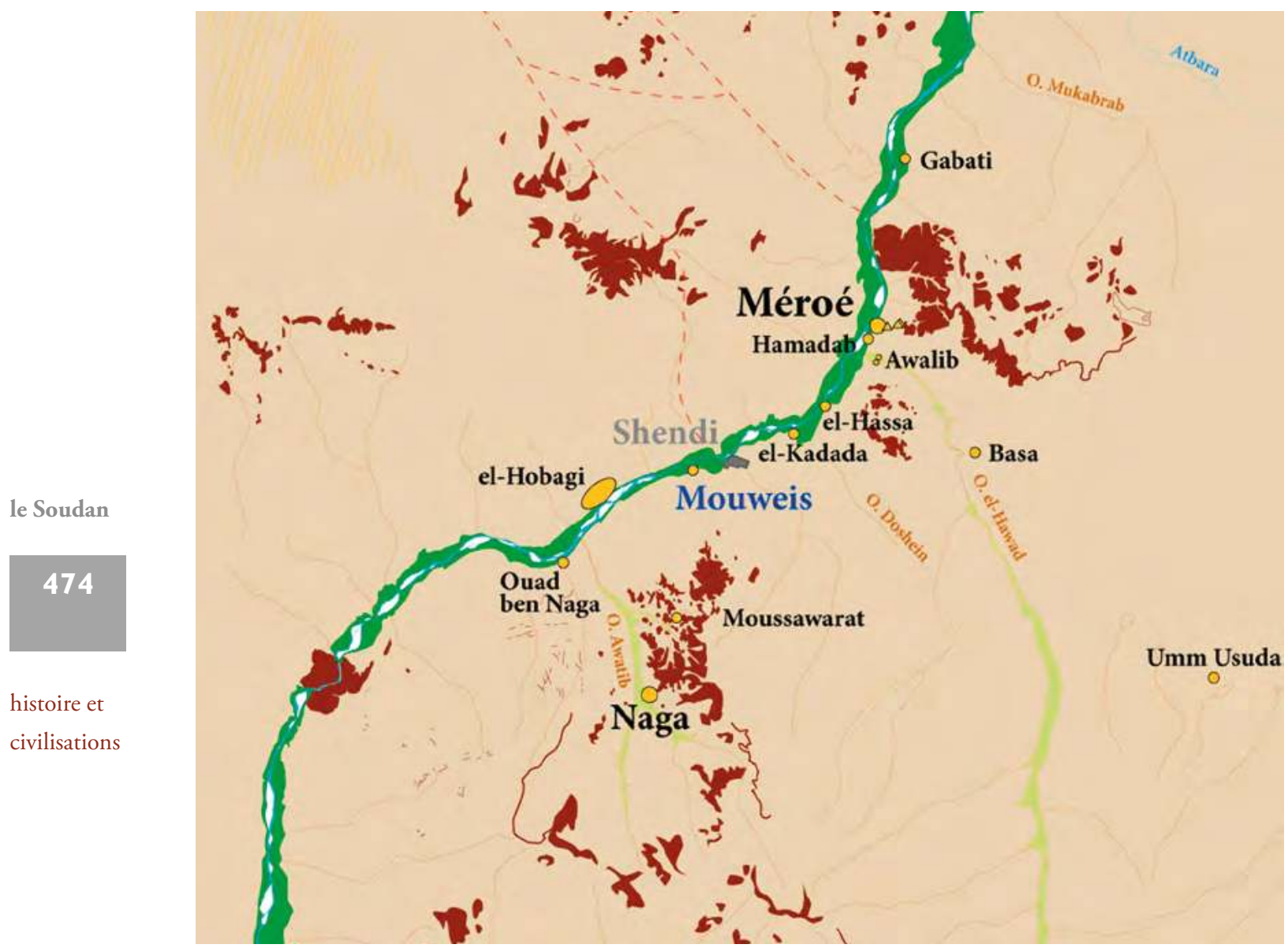

Figure 1 : Carte générale de la région de Méroé. 
Successeur du royaume de Napata qui se développa en Nubie jusqu'à la $4^{e}$ cataracte après le retrait des Égyptiens du Nouvel Empire, le royaume de Méroé émergea $500 \mathrm{~km}$ plus au sud, entre les $5^{\mathrm{e}}$ et $6^{\mathrm{e}}$ cataractes (figure 1). Centrée sur la plaine fertile de Shendi, au cœur de la région du Boutana, la capitale du royaume, Méroé, abrite également la nécropole royale aux fameuses pyramides. Ce transfert de capitale, de Napata à Méroé, serait l'œuvre du fondateur d'une nouvelle «dynastie», le souverain Arkamani I ${ }^{\text {er }}$, qui régna vers 270-260 avant J.-C. Le royaume de Méroé contrôlera jusqu'à $1600 \mathrm{~km}$ de la vallée du Nil, en suivant le cours du fleuve, de la région de Khartoum à la confluence des Nils Blanc et Bleu, jusqu’à la frontière avec l'Égypte.

Le royaume de Méroé livre, au sein de ses sites urbains, un nombre important de palais. C'est le cas de la capitale, Méroé, avec les deux bâtiments M 294-295 de la "cité royale» et la grande structure M750, annexe au temple d'Amon. On en trouve aussi plusieurs dans les centres religieux de Naga et du Gébel Barkal; des villes moyennes de «l'île de Méroé» comme Ouad Ben Naga, Mouweis ou el-Hassa (Damboya) en sont également pourvues. Sur le modèle pharaonique, les palais méroïtiques peuvent s'appréhender selon deux modèles fonctionnels: le palais cérémoniel, en principe placé à la droite du temple d'Amon et à sa perpendiculaire, soulignant l'union symbolique du roi et du dieu monarchique; la résidence administrative, comportant magasins et vastes pièces de vie. Certains de ces palais sont contemporains, ce qui implique que les souverains méroïtiques possédaient plusieurs résidences, et/ou que ces résidences étaient érigées au profit de gouverneurs ayant délégation du pouvoir royal. Depuis la découverte d'un palais sur le site méroïtique de Mouweis, on sait même que ces structures pouvaient être construites selon un schéma directeur très similaire (figure 2 ), le bâtiment en question présentant des similitudes frappantes avec celui de Ouad Ben Naga, érigé au cours du premier siècle av. J.-C.

Ce schéma directeur des palais royaux méroïtiques repose sur le plan carré classique à étages agencés autour d'un espace central, avec des magasins accessibles au sous-sol et des pièces représentatives à l'étage supérieur. Ce modèle de plan se retrouve au sein d'autres bâtiments monumentaux de l'architecture civile, notamment ceux de Méroé ou de Basse-Nubie. Les palais possèdent également des entrées sur chacune de leurs façades, ces voies d'accès étant agencées au sein de la structure selon des schémas préétablis. Ce modèle n'est cependant pas uniforme, et repose pour l'essentiel sur les trois palais, à savoir Ouad Ben Naga, Mouweis et B1500. En effet, dès le début de l'ère méroïtique, l'émergence de ce schéma architectural se décline 
en modèles autonomes. Les solutions architecturales sélectionnées sont standardisées, mais appliquées différemment selon la ou les fonctions envisagées du bâtiment final.

\section{un modèle architectural commun}

Les similitudes en plan de ces édifices sont nombreuses et pourraient indiquer l'existence d'un modèle architectural commun ${ }^{1}$. B 1500 du Gébel Barkal, le palais 100 de Ouad Ben Naga et le palais de Mouweis, tous de plan carré, intègrent des séries de pièces présentant des éléments communs. Parmi eux, les plus significatifs sont illustrés par des accès similaires composés d'une entrée monumentale à rampe menant à une grande salle rectangulaire rythmée par six colonnes ${ }^{2}$. L’ensemble est flanqué, à gauche et à droite de l'entrée, de travées de pièces allongées et étroites identifiables comme des caissons et des magasins. Depuis l'entrée monumentale, on accède à une pièce rectangulaire intermédiaire, une sorte de vestibule, séparant la cour centrale et l'entrée ${ }^{3}$.

J.Vercoutter avait, pour Ouad ben Naga, identifié ce vestibule à un sanctuaire 4 . Par comparaison avec le palais B150o, cette salle à piliers rectangulaires est très semblable dans la forme et la position à son homologue du B1500, présentant six piliers alignés en deux rangées ${ }^{5}$. Cette salle du palais B1500 fut identifiée par S. Donadoni à une salle de réception précédant la cour centrale. La similitude entre les deux pièces est renforcée par la présence de la rampe sur le côté ouest, conduisant au premier étage. La partie centrale du palais de Ouad ben Naga et de Mouweis présente également de très grandes similitudes, notamment dans l'épaisseur des maçonneries ${ }^{6}$. La présence commune d'un puits de lumière central, à la différence de la cour à péristyle du palais B 1500, renforce la standardisation du modèle. Sur la base de ces considérations, nous pouvons envisager un plan d'étage similaire pour ces structures contemporaines (fin du $\mathrm{I}^{\text {er }}$ siècle avant J.-C.- $\mathrm{I}^{\mathrm{er}}$ siècle après J.-C.) (figure 3).

Ce modèle à plusieurs étages, de plan carré et possédant des entrées aux points cardinaux, dont une entrée monumentale ouvrant sur le groupe salle hypostyle-vestibule-espace central, trouve son expression la plus évidente avec B1500 ${ }^{7}$. Ce palais constitue un jalon capital de ce modèle, pour deux raisons majeures. La première réside dans sa plateforme de fondation centrale, indiquant la planification d'un espace ouvert au cœur de l'édifice dès les prémices de la construction ${ }^{8}$ - à la manière du palais d'Apriès de Memphis érigé sur une plateforme de $13 \mathrm{~m}$ de côté ${ }^{9}$ - phénomène particulièrement innovant pour la période méroïtique. La seconde correspond à la cour à péristyle centrale à deux niveaux, 

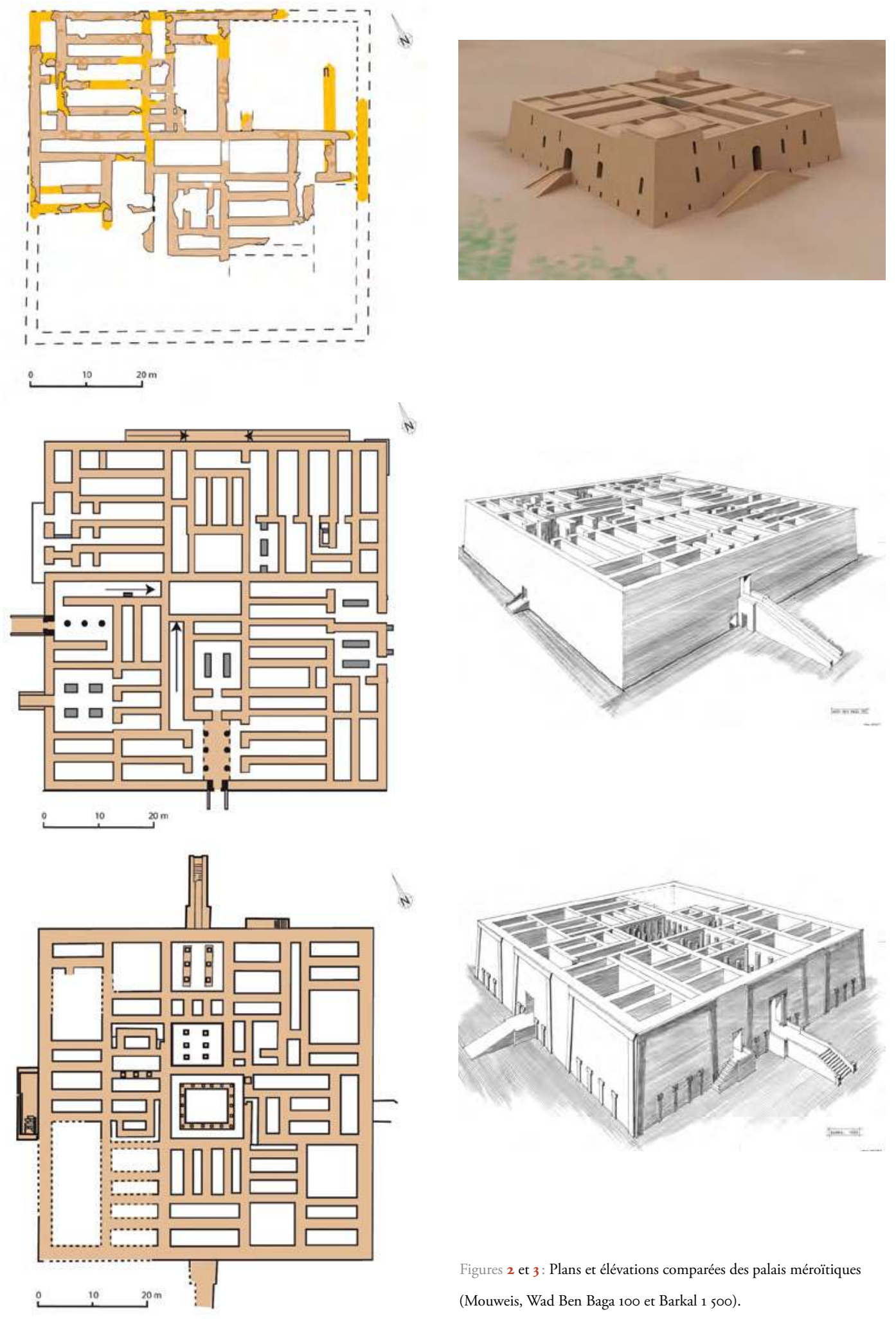

le royaume de Méroé, un monde urbain

Figures 2 et 3 : Plans et élévations comparées des palais méroïtiques (Mouweis, Wad Ben Baga 100 et Barkal 1 500). 
impliquant un recours régulier au bois, en particulier dans la zone située entre le portique inférieur et la seconde colonnade ${ }^{10}$. L'étude menée par S. Barberini a ainsi permis de restituer la présence d'un parapet surmontant l'entablement du portique inférieur et supportant les colonnes de la galerie supérieure $^{11}$. Cet héritage hellénistique est cependant modulé selon des méthodes locales, comme le rôle crucial joué par le mortier de jointoiement entre les bases des colonnes supérieures et la balustrade, permettant ce double niveau de colonnade, encore inédit ${ }^{12}$.

Vitruve décrit certains édifices romains richement décorés, conçus autour d'un péristyle à fonction officielle et servant de salle de réception ${ }^{13}$. Ceci indique en premier lieu que la fonction du péristyle dans l'architecture romaine se développe autour de la démonstration du prestige et du statut social, contrairement à la période hellénistique où le modèle est appliqué pour tous les types d'édifices, même les plus modestes ${ }^{14}$. Compte tenu de la datation du bâtiment B1500, il est probable que le palais méroïtique du Gébel Barkal s'inspire des exemples tirés principalement de la période romaine, passés par le filtre égyptien ${ }^{15}$. En outre, les contacts entre Romains et Méroïtes s'accentuent à la fin du premier siècle avant J.-C., lors du conflit d'Auguste en Basse-Nubie et des deux expéditions envoyées par Néron à Méroé ${ }^{16}$. Le rôle prépondérant joué par la ville de Philae dans les relations entre l'Égypte et la Nubie méroïtique ${ }^{17}$ est également déterminant, le site constituant un centre de pèlerinage important, permettant aux bâtisseurs nubiens de se familiariser avec la tradition romaine. Cependant, une telle innovation dans l'architecture ne saurait être le fruit du hasard, et implique l'impulsion du couple Natakamani-Amanitoré, fameux pour ses ambitieuses opérations de construction à grande échelle. La volonté d'ériger un bâtiment réellement nouveau a pu certainement influencer les palais postérieurs situés dans les provinces de plus petite taille et les centres urbains stratégiques, comme Mouweis.

Outre les éléments architecturaux mis en évidence, le palais B1500 se distingue également par la décoration particulièrement riche entretenant des liens étroits avec l'art hellénistique. Cela n'a rien de surprenant si l'on intègre la Basse-Nubie au royaume méroïtique, profondément liée au monde égyptien par une tradition séculaire de relations culturelles et politiques ${ }^{18}$. En Égypte, la coexistence de fortes traditions locales et de nouveaux éléments culturels issus de l'hellénisme a permis l'émergence d'un nouveau langage artistique mêlant fusions et reprises des moyens d'expressions aux sources multiples ${ }^{19}$. À ce titre, la décoration du palais B 1500 est unique et n'a pas d'égal dans la sphère nubienne ${ }^{20}$. Le palais B1500 devait également être le théâtre de rituels de renouvellement du pouvoir royal et probablement participer à la cérémonie d'intronisation ${ }^{21}$. La présence 
de la plateforme de fondation du B1500 confirme également le procédé, dans sa volonté de surélever le bâtiment ${ }^{22}$, non pour des raisons défensives, mais davantage pour accentuer la majesté de l'édifice tout en l'isolant des structures environnantes ${ }^{23}$. La distance séparant le palais du reste de la ville, aussi relative soit-elle à l'échelle d'un site tel que l'antique Napata, n'en est pas moins significative, mais peut s'expliquer plus prosaïquement par l'emprise nécessaire à une telle construction, impliquant la recherche d'une surface disponible suffisante hors du cœur de la cité du Gébel Barkal ${ }^{24}$.

On peut donc supposer que le palais de Natakamani (B1 500) inaugure véritablement un nouveau prototype d'architecture palatiale, de taille et de caractère originaux, dans lequel sont convoqués les éléments hellénistiques et romains à travers la médiation de l'Égypte tardive ${ }^{25}$. Ajoutons que le bâtiment devait être au centre d'un nouveau plan d'urbanisme, l'entrée principale sur le côté septentrional (atypique au regard des palais tardifs type Mouweis ou Ouad Ben Naga, dont l'entrée principale est méridionale) du bâtiment ouvrant sur une zone dense dont le palais B 2400 est le meilleur exemple (figure $4{ }^{2}{ }^{26}$. Les similarités de plan avec les autres palais datés à la transition du premier siècle de notre ère témoignent d'un modèle commun, modulable selon les prérogatives, comme le démontrent les innovations du B 1500 .

Les palais méroïtiques sont également liés à un temple, habituellement dédié à Amon. Les structures palatiales et cultuelles forment un ensemble connecté dédié partiellement aux cérémonies religieuses et royales. Certains de ces bâtiments ont également possédé une fonction résidentielle, comme l'a indiqué T. Kendall pour B1200 27 . Une typologie commune semble se dégager avec les édifices tardifs comme B1500, le ОвN 100 et le palais de Mouweis ${ }^{28}$, qui partagent certains éléments majeurs avec Barkal $\mathrm{B} 100$ et $\mathrm{B} 2400$ pour l'influence hellénistique du décor de $\operatorname{cour}^{29}$. Il n'est pour le moment pas possible de définir une date pour ce schéma directeur, ni de caractériser son évolution au fil du temps. Cependant, sur la base des dates attribuées à ces bâtiments, on peut supposer qu'il s'agit d'un modèle planimétrique couvrant une période allant du premier siècle avant J.-C. à la fin du premier siècle de notre ère ${ }^{30}$.

\section{le modèle et ses fonctions}

L'un des éléments centraux de la ville méroïtique est donc le palais royal. Bien qu'en de nombreux points les bâtiments nubiens soient très différents des parallèles égyptiens, on observe, en l'état actuel des recherches, une certaine continuité de la valeur symbolique de l'édifice. La mise en œuvre d'un nouveau palais est un événement majeur, car l'édifice représente 


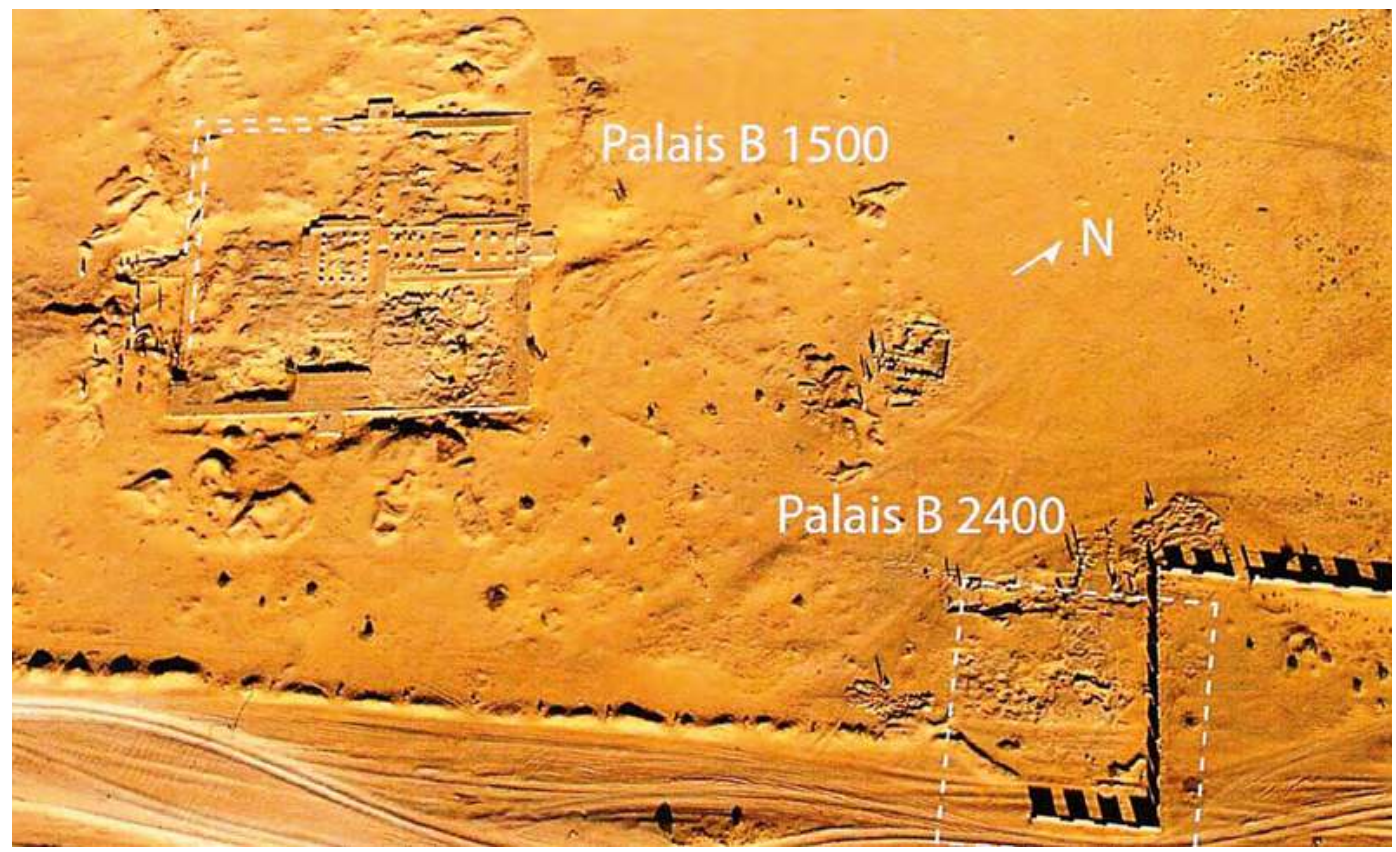

Figure 4: Vue aérienne des palais B 1500 et B 2400 de Barkal (d'après Baud 2010, fig. 110).

le Soudan
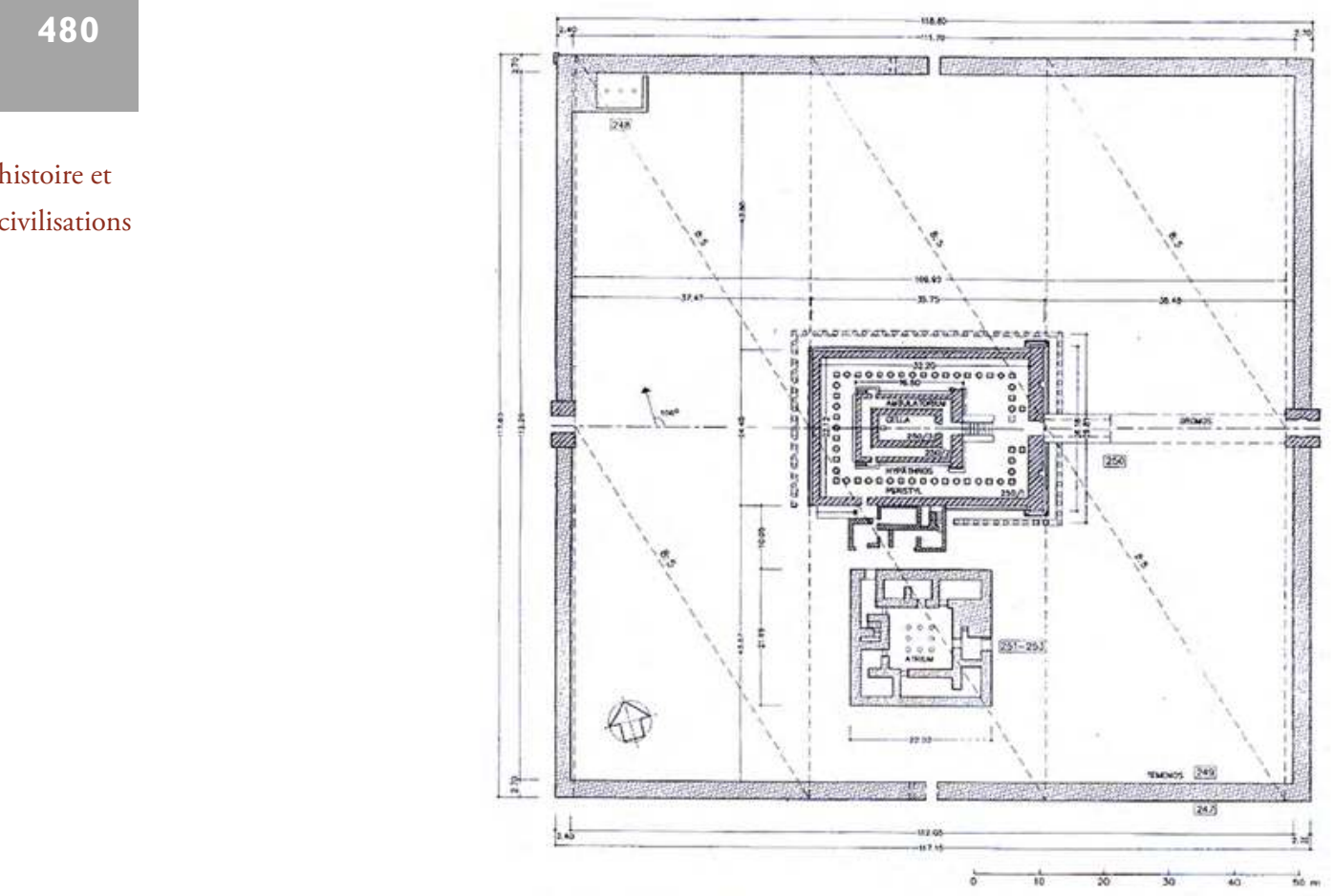

Figure 5: Plan du M 251-253 connecté au M 250 (d'après Hinkel et Sievertsen 2002, fig. IX.46). 
le rôle créateur du souverain, restaurateur de l'ordre du monde ${ }^{31}$. La structure doit donc incarner ces significations, en les manifestant dans ses aspects fonctionnels.

Les connaissances actuelles sur les structures de la Nubie palatiale sont loin d'être exhaustives, principalement en raison de l'état de conservation des bâtiments fouillés dont ne subsistent, le plus souvent, que les fondations et qui présentent rarement une élévation suffisante. La récupération systématique des matériaux de construction est également dévastatrice pour ces impressionnants bâtiments, devenus de véritables carrières à ciel ouvert une fois abandonnés ${ }^{32}$. L'objectif est donc ici de reprendre l'édifice palatial en tant que tel, pour tenter d'en définir la ou les fonctions mais également son insertion dans la trame urbaine. En effet, il apparaît impossible de définir ce qu'est un palais méroïtique sans observer tant sa symbolique que ses connexions les plus concrètes avec les autres édifices qui conditionnent le schéma même de la ville. À ce titre, on s'attachera à l'analyse de leur positionnement et de leur orientation par rapport au temple principal.

Pour ce faire, on ne peut malheureusement pas se restreindre à la seule sphère soudanaise, mais il convient également d'explorer le modèle égyptien, sans toutefois chercher à forcer la comparaison. Elle est cependant inévitable pour tenter d'identifier un modèle architectural de référence, tout en tenant compte des spécificités propres aux édifices nubiens. En effet, sous de nombreux aspects, la conception structurelle des bâtiments semble avoir pour modèle des principes propres à la civilisation égyptienne, et plus particulièrement les bâtiments d'époque pharaonique ${ }^{33}$.

L'Égypte pharaonique nous fournit quelques exemples d'architecture palatiale, en particulier au Nouvel Empire, période la plus documentée en ce qui concerne ce type de bâtiments. Chaque souverain, comme en Nubie, installe plusieurs palais dans les villes stratégiques, en particulier dans les capitales, dont les plus prestigieuses se dotent de nombreux édifices monumentaux. On peut ainsi supposer que les palais contemporains les uns des autres, comme au Gébel Barkal et à Méroé, peuvent être distingués selon leur fonction et leurs caractéristiques architecturales.

D'un point de vue strictement architectural, deux cas de figure sont possibles. Dans le premier cas, il s'agit d'une structure physiquement rattachée au temple, utilisée par le roi lors de certaines fêtes religieuses et érigée à des fins purement cérémonielles, comme à Médinet Habou $^{34}$. Le second type est complètement indépendant, et semble revêtir une fonction résidentielle, comme à Malqata ${ }^{35}$. D. O'Connor opéra par la suite une subdivision supplémentaire en trois modèles typologiques, fondée sur une différenciation des fonctions ${ }^{36}$. Le premier modèle 
correspond au palais cérémoniel, abritant les cérémonies religieuses, comme par exemple dans le palais nord d'Amarna et dans le palais de Mérenptah à Memphis. Le deuxième modèle correspond à un palais de gouvernorat, dédié à la gestion du territoire qui lui est associé, comme la maison du roi d'Amarna et certains des bâtiments rattachés aux temples funéraires d'époque ramesside.

Selon D. O'Connor, les bâtiments gouvernementaux ou cérémoniels n'ont pu revêtir de fonction résidentielle — bien que les appartements royaux soient attestés dans les édifices —, de même que les salles de réception et les pièces de bain. Le bâtiment résidentiel le mieux connu est celui du pharaon Amenhotep III à Malqata en Thébaïde, qui constitue pour D. O'Connor le troisième modèle. En supposant que cette distinction typologique soit correcte ${ }^{37}$, il n'est malheureusement pas possible d'appréhender une telle différenciation pour les bâtiments méroïtiques, en raison des lacunes documentaires et de l'état des structures lors de la fouille. En dépit de ces limitations, on peut envisager quelques considérations sur certaines structures dont la fonction peut être assumée, comme dans le cas du Barkal 1500.

Pour effectuer une première comparaison entre le palais du Nouvel Empire égyptien et son homologue méroïtique, on tiendra compte de la distinction entre les deux premiers types, à savoir le bâtiment rattaché à la cérémonie cultuelle et le type résidentiel indépendant. Le premier type n'est pas attesté à l'époque méroïtique, mais certains bâtiments sont érigés à proximité du temple, sans pour autant y être rattachés. C'est le cas du M 251253 de Méroé, situé dans l'enceinte sacrée du temple, près du temple d'Amon M 250 (figure 5) ${ }^{38}$. Compte tenu de leur position, la connexion entre le palais et le temple est tout à fait évidente et pourrait indiquer que le palais a été utilisé par le roi lors de certaines fêtes religieuses. Dans ce cas, comme pour les palais du Nouvel Empire, nous pouvons être en présence d'un bâtiment dédié aux cérémonies rituelles ponctuelles, qui tient également lieu de palais cérémoniel, sorte d'extension de l'édifice sacré. L'implantation des deux bâtiments au sein du même temenos ne peut être fortuite, ce qui souligne encore davantage la relation étroite entre les deux structures.

Sur le plan architectural, des similitudes fondamentales apparaissent en plan entre ce bâtiment et ses équivalents égyptiens. Le plan quadrangulaire organisé autour d'une cour centrale à colonnes ${ }^{39}$, conçue comme une salle d'audience ou de réception, peut également être perçu comme l'intégration d'une salle du trône ${ }^{40}$. En Nubie méroïtique, même si les exemples tels que le palais M 251-253 de Méroé sont rares, on peut considérer que tous les bâtiments palatiaux ont été en relation avec le temple principal de la ville. 
Le second type de construction du Nouvel Empire, indépendant du temple et possédant une fonction résidentielle ${ }^{41}$, est bien illustré en Égypte par l'exemple de Malqata ${ }^{42}$. Les quelques exemples égyptiens connus possèdent un plan rectangulaire, inclus au cœur d'un ensemble urbain dont il constitue l'un des composants majeurs. Sur la base des preuves archéologiques, l'organisation de ces édifices est basée sur la division structurelle entre secteurs publics et privés, formalisée par une symétrie interne. Les secteurs publics sont connectés directement à la résidence royale et sont composés de plusieurs compartiments hypostyles et d'une salle du trône ${ }^{43}$.

À l'époque méroïtique, un bâtiment palatial de plan carré pourrait s'inscrire dans cette lignée de palais résidentiels. M750 de Méroé - fouillé par J. Garstang au début des années $1900^{44}$ — prend position hors du mur d'enceinte qui encadre la zone sacrée centrée autour du temple d'Amon M260 (figure 6) ${ }^{45}$. Malgré son lien évident avec le temple, l'implantation d'une résidence royale dans un secteur d'habitation externe au temenos pourrait indiquer une utilisation partiellement résidentielle de l'édifice, différente de celle du M294-295. La position du M750 sur le côté droit du temple indique toutefois une connexion claire, mais suffit-elle à le désigner comme palais cérémoniel? ${ }^{46} \mathrm{Il}$ s'agit en effet d'une implantation «réglementaire», mais les données archéologiques publiées ne permettent pas de confirmer la tenue de fêtes de grande ampleur au sein du palais.

\section{I’héritage égyptien : un parallèle pertinent mais limité}

Le palais du Nouvel Empire revêt une signification bien particulière dans la conception égyptienne, et plusieurs de ces aspects sont transmis à l'architecture palatiale nubienne ${ }^{47}$. Les pharaons égyptiens ne se contentent pas d'un seul bâtiment mais disposent de plusieurs palais, et ce dans plusieurs cités royales, comme Thèbes, Memphis et Pi-Ramsès ${ }^{48}$. Pour les Égyptiens, le palais royal intègre de fortes significations symboliques ${ }^{49}$ retranscrites en plan et dans le décor. Ceci nous permet d'adopter une grille de lecture judicieuse, si elle est prise avec précaution, pour comprendre le rôle des palais nubiens au sein de la ville.

La relation entre les traditions locales et les concepts égyptiens est évidente dans les textes, particulièrement pour ce qui concerne la légitimation du pouvoir royal et les rituels de couronnement où des éléments purement égyptiens sont liés à la monarchie nubienne ${ }^{50}$. Le grand nombre de résidences royales est ainsi interprété comme l'indice d'un couronnement rituel kouchite incorporant l'empreinte égyptienne aux traditions locales antérieures. L'investiture royale consiste en une série de rituels à travers lesquels le roi assume sa fonction royale et divine au cours d'un voyage 
le Soudan

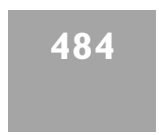

histoire et civilisations

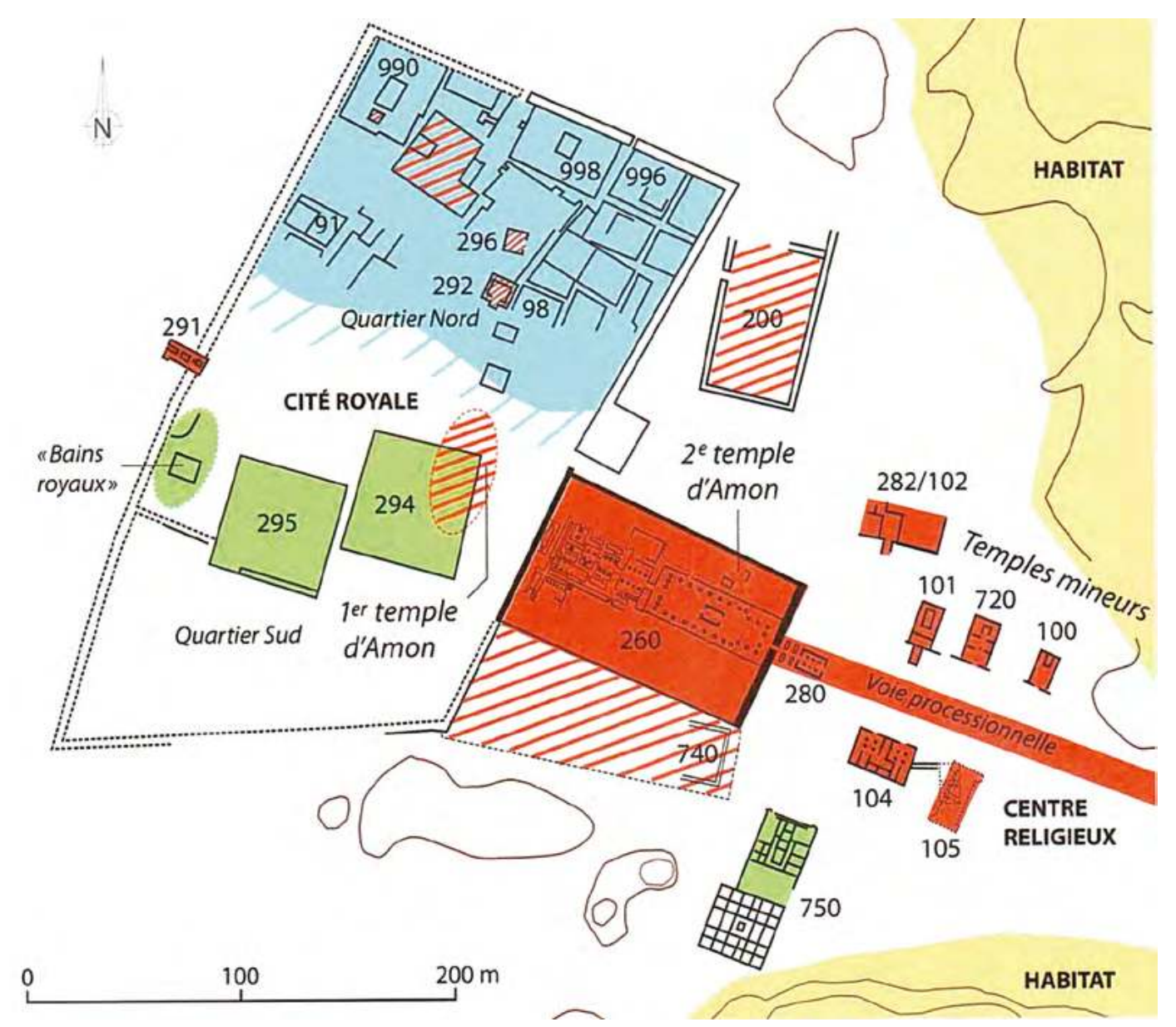

Figure 6: Détail du centre-ville de Méroé (d'après Baud 2010, fig. 57). 
cérémoniel s'étendant sur tout le royaume. Ce rituel intronise et légitime le nouveau souverain dans la capitale, les temples d'Amon qui jalonnent la route entre Napata et Méroé constituant des étapes intermédiaires ${ }^{51}$.

Les textes décrivant la cérémonie du couronnement démontrent le rôle prépondérant du dieu Amon, en particulier à Napata, dans l'affirmation de la légitimité du roi ${ }^{52}$. Le couronnement du roi kouchite est un processus long et complexe impliquant une véritable procession dans les temples majeurs du territoire. Ce rituel initiatique débute généralement à Napata pour se rendre à Méroé, via les temples intermédiaires comme celui d'Amon à Kawa, et à Pnoubs. Il semble toutefois que dans certains cas ce processus ait été inversé, la procession allant de Méroé à Napata, comme l'indiquent l'inscription d'Iriké-Amanoté ${ }^{53}$ et celle de Nastasen ${ }^{54}$. Ce changement d'itinéraire peut être lié à l'importance grandissante de la ville de Méroé, significative depuis les débuts de la XXV ${ }^{e}$ dynastie, bien que Napata ait toujours conservé un rôle majeur lors du sacre ${ }^{55}$. Même lorsque la capitale fut transférée à Méroé, ce rôle ne disparaît pas, comme en témoignent les divers cimetières royaux situés près de Napata. Ces derniers abritent les complexes funéraires kouchites, comme celui de Piankhy ${ }^{56}$ dans la nécropole d'el-Kourrou.

L'inscription d'Iriké-Amanoté à Kawa décrit le voyage du souverain depuis Méroé jusqu’à Napata (section 5, cols. 35-43). Après un voyage de 9 jours, le roi est conduit vers le temple d'Amon et semble directement mené vers le sanctuaire où il reçoit, à la manière d'un Königsorakel, le pouvoir universel par la rencontre intime avec le dieu: $\mathbb{R}$ Puis, il arriva à la montagne sacrée (Gébel Barkal) le troisième mois de l'été, et se rendit à la résidence royale pour recevoir la couronne cérémonielle de Nubie. Puis il se rendit au temple de son père, Amon-Rê, qui réside dans la montagne sacrée (Gébel Barkal). Sa Majesté dit au dieu: "Je suis venu devant toi, mon noble père, père des dieux, pour que tu m'accordes la royauté sur le pays des DeuxTerres, car tu es le roi bienveillant des dieux et des hommes." Puis ce noble dieu dit: "Je te donnerai la royauté comme seigneur des Deux Terres." $\gg\rangle$ (col. 37-41) Le couronnement est suivi d'offrandes au dieu et au clergé. IrikéAmanoté demeure plus d'un mois à Napata, tout comme Nastasen. La raison principale de ce séjour réside peut-être dans la célébration du Nouvel An durant le premier mois de l'inondation, et la confirmation du pouvoir royal au commencement de la seconde année de règne ${ }^{57}$. Son voyage est comparé au voyage de Rê qui, dans sa course, rétablit l'ordre du monde ${ }^{58}$. Il apparaît ici comme créateur et souverain universel.

La section 7 de l'inscription (cols 49-55) décrit les cérémonies de couronnement à Kawa, dans le temple d'Amon. L'Amon de Napata accorde la royauté au souverain et ce dernier reçoit l'arc et les 
flèches du dieu en signe de pouvoir universel (col. 50-52: 《 Sa Majesté se rendit au temple de son père Amon-Rê de Kawa, et présenta une grande offrande de pain, de bière, de boufs et d'oiseaux, de toute bonne chose. Puis ce dieu lui dit: "Je t’ai donné toutes les terres, au sud, au nord, à l'ouest et à l'est." Puis lui fut donné un arc avec ses flèches de bronze $\gg$ ). Le dialogue entre le dieu et le roi correspond également à un Königsorakel, ce qui identifie la cérémonie de Kawa à un rituel de couronnement.

À Méroé, au sein du palais M 294, des objets votifs portant les cartouches d'Aspelta, Armateqlo, Malonaqen et Karkamani nous offrent l'opportunité de présenter l'hypothèse suivante: ces objets correspondent peut-être à des donations royales au dieu Amon lors de la fête du Nouvel $\mathrm{An}^{59}$, bien que l'existence d'une telle fête ne soit aucunement avérée à Méroé. En Égypte, cette fête coïncide avec le début de la crue du Nil et est probablement liée à la conception pharaonique de la royauté, dont nous observons ici une continuité forte ${ }^{60}$. Au Nouvel Empire, le jour du Nouvel An correspond à la journée traditionnelle du couronnement de Pharaon, bien que l'intronisation soit déjà effectuée. Ainsi, la découverte de ces objets à Méroé, qui se réfèrent potentiellement à cette fête du Nouvel An, peut indiquer que cette célébration et l'anniversaire du couronnement avaient lieu dans la ville de Méroé ${ }^{61}$. Ceci serait alors déterminé par le fait que l'étape initiale de l'intronisation était effectuée à Méroé, au moins à certaines périodes ${ }^{62}$. Sur la fonction politique des autres établissements visités au cours de ce voyage, les textes ne fournissent pas d'informations précises. On peut supposer que plusieurs villes accueillant une étape de la cérémonie du couronnement ne sont pas mentionnées dans les textes, au regard de la découverte régulière d'autres résidences palatiales.

Après le couronnement à Napata ou Méroé, le roi devait probablement entreprendre une visite de tous les principaux sanctuaires du royaume ${ }^{63}$ afin d'affirmer le pouvoir royal dans les principales villes et restaurer l'ordre dans toutes les provinces, après la période de chaos commencée à la mort de son prédécesseur. Ces villes n'ont probablement pas été sélectionnées arbitrairement. Elles devaient correspondre aux capitales des provinces dont l'union a donné naissance au royaume de Kouch. Ce procédé démontre également l'importance de la ville, en tant qu'entité consubstantielle à la royauté, contrairement à la tradition égyptienne favorisant le rôle du temple lui-même. Ce point est d'ailleurs bien défini par S. Wenig ${ }^{64}$, qui indique que la transformation d'un centre religieux majeur en ville est une progression systématique à l'époque méroïtique. 


\section{la relation temple-palais}

Bien qu'il soit fondamental de considérer ces structures palatiales individuellement, elles ne peuvent être comprises hors de leur contexte urbain. Il est donc indispensable de les replacer dans leur connexion avec le temple, cette relation conditionnant la colonne vertébrale de la ville. Une ville royale est avant tout caractérisée par la présence d'un temple principal, habituellement dédié au dieu Amon, et éventuellement d'autres plus réduits, et par la présence d'un ou plusieurs palais, comme au Gébel Barkal ou à Méroé ${ }^{65}$. Certains possèdent un caractère résidentiel indéniable, d'autres une fonction principalement protocolaire, et ils centralisent la gestion des ressources et des biens. En outre, les bâtiments sont érigés en fonction de la connexion forte souhaitée entre eux et le temple, soulignant la relation étroite entre la maison du dieu et celle du roi ${ }^{66}$. Temples et palais sont reliés par des voies monumentales, parfois soulignées de statues de béliers, suivant le modèle des villes pharaoniques.

L'application du schéma égyptien hérité du Nouvel Empire aux bâtiments méroïtiques soulève des similitudes pertinentes qui renforcent l'idée d'une conception architecturale similaire à celle de l'époque pharaonique, tant dans la signification profonde que dans l'identité fonctionnelle ${ }^{67}$. Le parallélisme entre les bâtiments Nubiens et Égyptiens est renforcé par leur implantation dans la trame urbaine et plus particulièrement vis-à-vis du temple principal. La relation étroite entre l'orientation du palais et le temple d'Amon est similaire à celle observée en Thébaïde entre les palais et le grand temple d'Amon de Karnak ${ }^{68}$. Toutefois, le comparatif ne peut faire l'économie d'un raisonnement en négatif, puisqu'un certain nombre de différences sont observables. Du point de vue structurel et dans la disposition, les différences sont nombreuses. Comme nous l'avons vu précédemment, deux types de palais sont observables en Égypte: l'un est rattaché au temple et l'autre est complètement indépendant ${ }^{69}$.

Aucune de ces deux catégories n'est reflétée fidèlement à l'époque méroïtique, où de tels exemples palatiaux ne sont jamais rattachés physiquement au temple. La relative exception pouvant confirmer la règle est le palais M 251-253 de Méroé qui, sans être rattaché au temple, est construit à proximité immédiate, encadré par le même mur d'enceinte ${ }^{70}$. Les autres bâtiments connus sont indépendants, même si leur lien avec le temple est toujours assez évident, comme dans le cas du B1200, près de l'angle occidental du temple B $800^{71}$.

Le deuxième type de palais égyptien, indépendant du temple, n'est connu qu'à Malqata, qui, construit pour le jubilé d'Amenhotep III, n’a presque rien de commun avec les bâtiments méroïtiques. 
Une telle synergie entre temple et palais ne peut cependant être uniquement le fruit d'une pure importation égyptienne. En effet, la relation existant entre Amon (de Napata et autres, issu de la fusion de l'Amon égyptien et d'une forme nubienne ancienne de la figure du bélier), le Nil et le souverain est nubienne et antérieure au Nouvel Empire ${ }^{72}$. La Nubie est d'ailleurs le lieu d'où provient l'inondation selon les Égyptiens (d'où le réseau de temples rupestres, s'insérant dans une géographie sacrée de la crue - et pas seulement manifeste d'une domination politique). Ce concept local est ensuite constamment reformulé sous influence égyptienne ${ }^{73}$.

L'un des événements majeurs conditionnant cette relation temple-palais est directement liée à la $\mathrm{XXV}^{\mathrm{e}}$ dynastie où le royaume est organisé autour d'une série de complexes groupant palais royaux et temples d'Amon, chaque région étant donc une image du tout, de l'ordre spatial articulant l'ordre social ${ }^{74}$. Le roi est couronné de manière indépendante dans les divers grands sanctuaires d'Amon (Napata, Kawa, Pnoubs-Kerma), ce rituel de couronnement suivant un itinéraire canonique débutant à Méroé ou Napata. La royauté elle-même pouvait également, dans ses pratiques, être "ambulatoire» ${ }^{75}$, bien que les données épigraphiques ou administratives fassent défaut. La stèle triomphale de Piankhy démontre, avec le départ initié le jour de la fête du Nouvel An, que le roi est celui qui apporte l'inondation d'étape en étape, vers le nord, tout en recevant la légitimité donnée par les dieux d'Égypte ${ }^{76}$. La multiplication des temples d'Amon, ou de temples avec ce culte en annexe, dans le maillage administratif des centres urbains possédant une résidence royale (ce qui est probablement le cas de Sedeinga, Semna, Bouhen, Faras, etc.), montre bien l'importance de cette association roi-Amon ${ }^{77}$. Méroé, à sa fondation au viII ${ }^{\mathrm{e}}$ siècle av. J.-C., obéit également à ce schéma, puisque son temple est alors un temple d'Amon de Napata. Le phénomène est identique vers le sud, comme nous pouvons l'observer avec les fouilles récentes des temples de Dangeil ${ }^{78}$ et d'el-Hassa ${ }^{79}$. Logiquement, nous découvrons sur ces mêmes sites la présence de "nouveaux" palais, avérée à el-Hassa (Damboya) et de même à Mouweis ${ }^{80}$.

Le palais est généralement positionné à la perpendiculaire des temples, comme on l'observe avec B1200 et les temples d'Amon B 500 et B 800 , tout comme à Méroé avec le palais M750 et le temple M 250. Ceci constitue pour L. Török la preuve de déterminants théologiques de l'architecture urbaine, ou plus exactement du maillage urbain. La position de la résidence royale, face à l'avenue processionnelle et du côté «tribord» (droite), selon la tradition égyptienne ${ }^{81}$, confirme le processus. La position du temple lui-même est déterminée par la montagne, perçue comme la résidence du dieu, comme à Naga ou au Gébel Barkal ${ }^{82}$. Le culte d'Amon est d'ailleurs double ${ }^{83}$, à la fois dédié à l'Amon de Thèbes, dont l'Amon nubien est une forme, 
et envers un dieu criocéphale, hypostase d'Amon. Cette divinité ancienne, purement nubienne, devait être vénérée de longue date dans ce contexte naturel de grottes ${ }^{84}$. On retrouve le même phénomène au temple A de Kawa, dédié à l'Amon de Kawa côté tribord et à l'Amon de Thèbes côté bâbord. C'est également le cas à Naga, avec l'Amon vénéré au temple égyptien, la montagne permettant l'élévation vers le mont primordial et un probable ancien culte local lié au Gébel ${ }^{85}$. L'orientation astronomique ${ }^{86}$ expliquerait les légères variations observables selon les époques dans l'orientation des temples, comme celui d'Apédémak (à Musawwarat, Basa, Naga, l'orientation est est-sud-est, de 120 à $135^{\circ}$ ). Cette orientation astronomique reste coordonnée au milieu naturel, à savoir le fleuve et le relief ${ }^{87}$. Il existe par ailleurs une hiérarchie entre temples, avec une orientation de la structure principale et la position perpendiculaire des chapelles-petits temples, comme à Kawa (temple T et A-B) et Méroé (série de chapelles) ${ }^{88}$.

Nous retrouvons ce principe à Mouweis dans le cadre de la fouille du petit temple J (figure 7 ) $^{89}$. Consistant en un bâtiment rectangulaire long de $12 \mathrm{~m}$, le plan symétrique correspond à celui d'un temple. Son sanctuaire contient un piédestal en grès blond destiné à accueillir le naos ou la barque du dieu. Dans la pièce voisine ouest, des fragments de décoration murale, réalisée en relief dans un mortier et rehaussée de couleurs, présentent le roi, la candace, le prince et les divinités associées, ainsi que deux morceaux de cartouches d'un même personnage, l'un en hiéroglyphes égyptiens, l'autre en hiéroglyphes méroïtiques ${ }^{90}$. Le prince en question correspond à Araka(n)kharor, soit à son frère Arakakhataror, tous deux fils du couple Natakamani et Amanitoré ( $\mathrm{I}^{\text {er }}$ siècle ap. J.-C.) ${ }^{91}$. À proximité du temple J, un massif de briques cuites appartenant à un autre édifice fut découvert ${ }^{92}$. L'orientation sud-est nord-ouest de «M», sans doute placé à la perpendiculaire du Nil de l'époque, pouvait indiquer qu'il s'agissait du sanctuaire principal de la ville, bien que les dernières campagnes aient infirmé ce postulat. Le massif dégagé semble en effet trop réduit pour les dimensions canoniques supposées (basées sur les parallèles méroïtiques), et la fouille archéologique n'a pas permis la découverte d'un plan clairement lisible ${ }^{93}$.

L'emplacement du temple $\mathrm{J}$, à l'est du sondage $\mathrm{M}$, et son orientation perpendiculaire à ce dernier, laissent supposer qu'une voie processionnelle, menant au temple principal, était bordée de sanctuaires mineurs, comme «J» ${ }^{94}$. On peut donc s'attendre, sur le modèle habituel des temples dédiés à Amon, à la présence d'un kiosque sur cette allée sacrée, ainsi que de socles destinés à surélever des béliers, disposés par paires se faisant face. La découverte de boucles de béliers dans le secteur confirmerait un tel aménagement ${ }^{95}$, tout comme à el-Hassa, mais malheureusement dans un état bien plus fragmentaire (figure 8). 


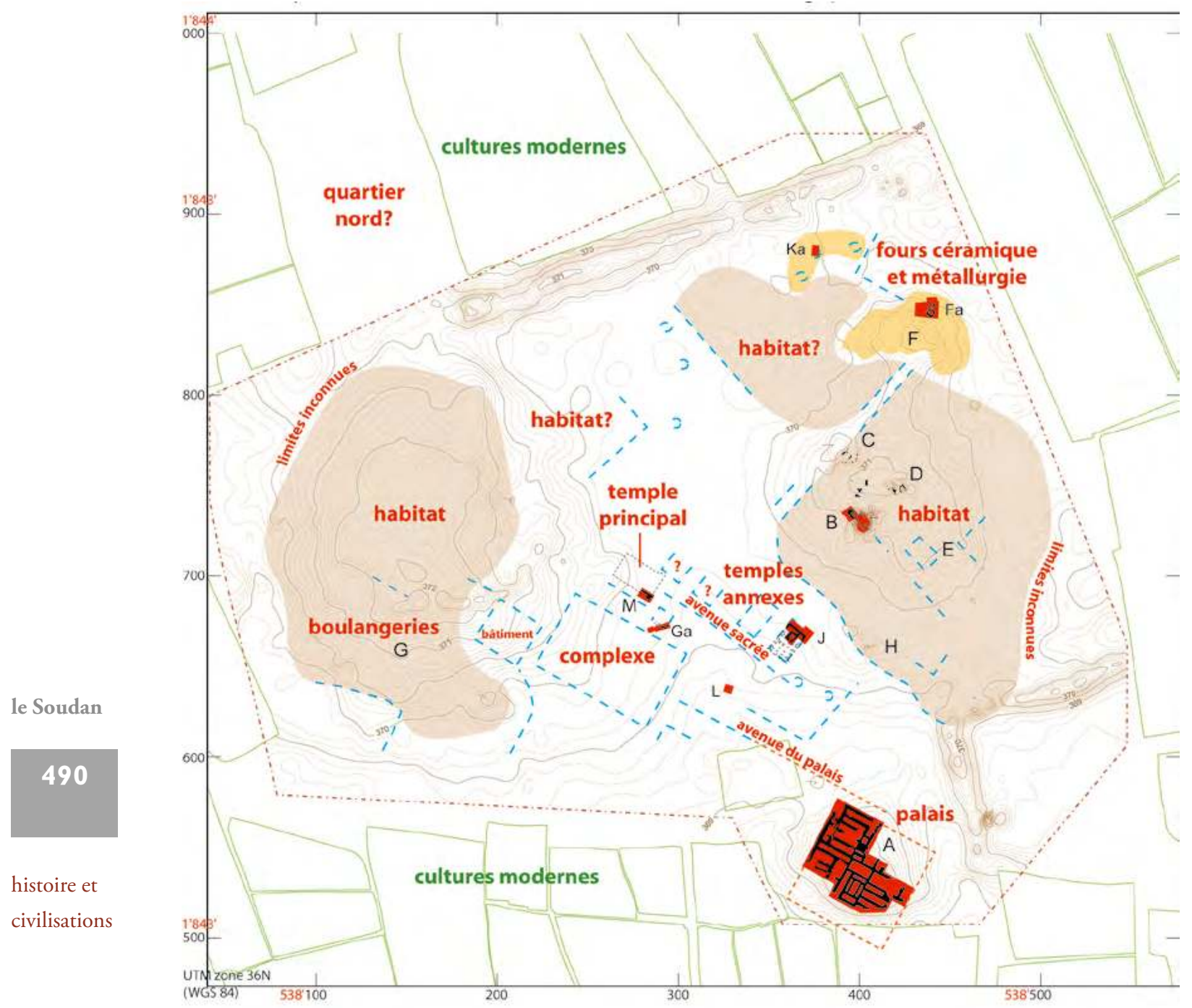

Figure 7 : Plan synthétique de la ville de Mouweis (cartographie: M. Baud; topographie: S. Aussel).

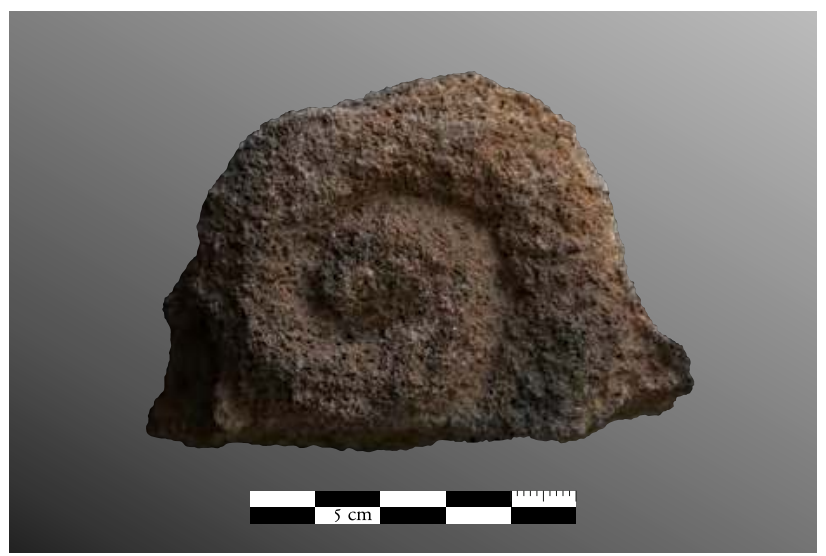

Figure 8: Fragment

de boucle de bélier

en grès (Mouweis,

temple J, Jo14-O2). 
Des éléments récents semblent étayer cette hypothèse. Un complexe monumental de $59 \mathrm{~m}$ de côté — identifié par magnétométrie en $2008^{96}$ et fouillé depuis 2012 dans le centre-ville ${ }^{97}$ — paraît partager une orientation similaire avec le palais royal $\left(28,5^{\circ}\right.$ nord). Ces deux structures pourraient être connectées par une avenue qui serait dès lors l'axe principal de la ville ${ }^{98}$. Il n'est d'ailleurs pas anodin que cette avenue borde la façade septentrionale du palais, selon le modèle pharaonique mentionné plus haut, à savoir sur le côté droit. Il n'est donc pas surprenant que le palais de Mouweis comporte une rampe d'accès (fondée sur caissons) sur son côté nord, menant directement au second étage depuis l'extérieur de l'édifice ${ }^{99}$. Ce complexe pourrait donc être considéré comme le temple principal de la ville. Cependant, tout ceci n'est pour le moment que conjectures, étant entendu que les fouilles du musée du Louvre sur ce secteur sont encore en cours.

En tous les cas, si cet ensemble de bâtiments est associé au palais royal mentionné supra par une allée processionnelle, nous sommes en présence d'un exemple du vaste programme de construction initié au tournant du premier siècle de notre ère par le couple Natakamani-Amanitoré ${ }^{100}$. Ce centre-ville a donc permis de modeler le site de Mouweis selon les codes régissant la trame urbaine d'une ville royale ${ }^{101}$, intégrée à un réseau urbain régional ${ }^{102}$. La fameuse "chaîne des installations étatiques" placée le long de la rive droite du Nil Moyen serait ainsi vérifiée ${ }^{103}$.

Le temple est également souvent complété d'un kiosque, comme à Kawa, situé dans l'axe du temple T. C'est également le cas à Naga, et probablement à el-Hassa et Dangeil, attestant du culte processionnaire d'Amon avec la barque solaire ${ }^{104}$. La présence de reposoirs à barque est d'ailleurs attestée, comme la structure B 504C du Gébel Barkal ${ }^{105}$ et les trois reposoirs du temple sud-est de Ouad Ben Naga ${ }^{106}$, ce qui montre également l'interconnexion entre sanctuaires. À titre d'exemple, mentionnons la relation particulière entre Barkal et Sanam Abou Dôm qui perdure après le changement de nécropole Kourrou-Nouri, sites d'ailleurs placés à distance équivalente de leurs sanctuaires «dynastiques» respectifs ${ }^{107}$. L. Török explique cela par le mélange d'une très grande cohérence et d'une véritable indépendance par rapport au modèle dans l'implantation des sanctuaires ${ }^{108}$.

Pour L. Török, les différences d'axe relèvent de ce mélange entre topographie (avec axe processionnel majeur) et astronomie, ellesmêmes déterminées par le type de culte impliqué ${ }^{109}$. Ce lien est très fortement accentué à Méroé, avant le III ${ }^{\mathrm{e}}$ siècle av. J.-C., entre le culte d'Amon et celui de la crue. Il est manifesté par la présence du sanctuaire de l'eau M194-195, orienté selon le Nil, où l'axe nord-sud traverse la porte nord en direction du temple d'Isis, et du nouveau temple M 600 adossé à l'enceinte de la ville royale. L. Török ${ }^{110}$ relie cette association à la figure d'Apédémak, 
dieu-guerrier mais également dieu fertile, et plus précisément god of the lifegiving water, connecté à la construction des hafirs. Cette ambivalence est illustrée à Musawwarat es-Sofra avec le temple du Lion, joignant la figure d'Amon à celle d'Apédémak ${ }^{111}$.

Ce sanctuaire de l'eau M194-195 contenait un bassin en pierre de deux mètres de long, et l'écoulement des eaux était assuré par un réseau dense de canalisations, reliées pour certaines d'entre elles au palais antérieur au M295. Le bassin est interprété comme une source symbolique du Nil ${ }^{112}$, et présente une décoration hellénisante associée au culte des ancêtres, directement inspirée du culte dynastique ptolémaïque ${ }^{113}$. Il est d'ailleurs intéressant de noter la découverte, au sein d'une cachette — située au niveau du palais antérieur au M295 (et probablement connecté au sanctuaire de l'eau) — d'objets votifs comme des sistres et des amulettes ankh, offerts lors de la cérémonie du Nouvel An par le souverain depuis Senkamanisken (deuxième moitié du viI ${ }^{\mathrm{e}}$ siècle av. J.-C.) jusqu'à Siospiqo (début du v viècle av. J.-C. ${ }^{114}$. Ceci constitue un bon exemple démontrant la relation entre les vertus fertiles d'Amon, associé à l'inondation, et la figure royale du souverain, perçu comme le fils du dieu ${ }^{115}$.

Si l'on suit l'hypothèse présentée, il existe un parallèle idoine avec le double bassin de Barkal B 2200 (figure 9), pouvant peut-être associer la figure royale lors de la fête du Nouvel An avec le culte osirien de Khoiak ${ }^{116}$, particulièrement adéquat lors de la célébration de l'inondation. Précisons immédiatement que ces références ne sont pas formellement démontrées dans les textes disponibles, et qu'il ne s'agit ici que d'une interprétation. B2200 serait relié de façon similaire au palais B1500, comme une véritable extension cultuelle du palais, ce qui pourrait être le cas du M194-195 de Méroé avec le palais antérieur au M295. Ceci ne ferait que renforcer le poids de la liturgie égyptienne dans le culte royal méroïtique. La présence du double bassin dans le complexe B 2200 pourrait également refléter la nature duelle du dieu fertile, mais également la double fontaine associant figure royale et crue du Nil ${ }^{117}$. Le double bassin du B 2200 pourrait ainsi être perçu comme une représentation physique de la double fontaine associant pouvoir royal et crue du Nil, selon le rituel osirien de Khoiak ${ }^{118}$, célébrant la personne funéraire et royale ${ }^{119}$. Il ne s'agit pas là d'une interprétation différente de celle qui a été proposée par la mission italienne, mais plutôt d'un prolongement de celle-ci, puisque la relation entre le mythe osirien et la figure du lion est bien connue ${ }^{120}$. La décoration des tables à libation égyptiennes démontre parfaitement cette tradition bien ancrée ${ }^{121}$, puisqu'elle associe le culte de l'inondation avec des figures et protomes de lions ${ }^{122}$, chose monnaie courante à la période ptolémaïque car les crues nilotiques sont associées au signe du lion de par la position du soleil dans les constellations ${ }^{123}$. On retrouve également la figure du lion sur les fontaines 


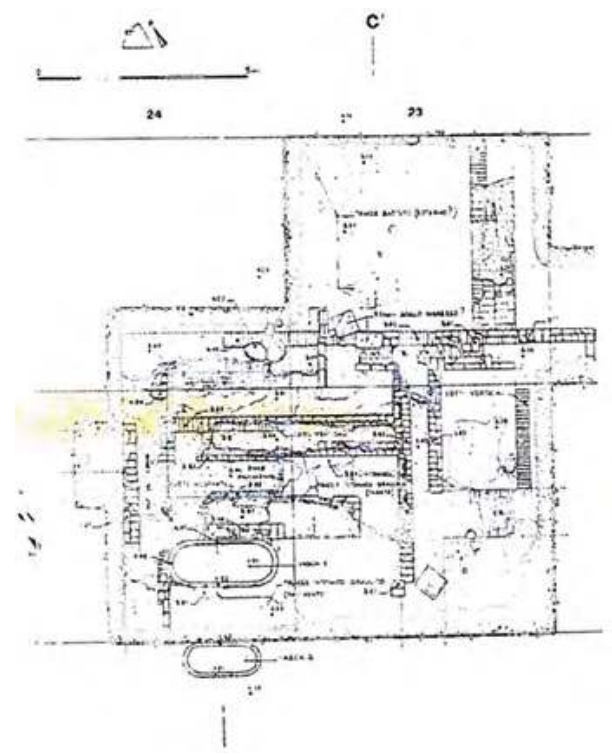

Figure 9: Plan du B 2200 de Barkal (d'après Sordi 2010, fig. 2).
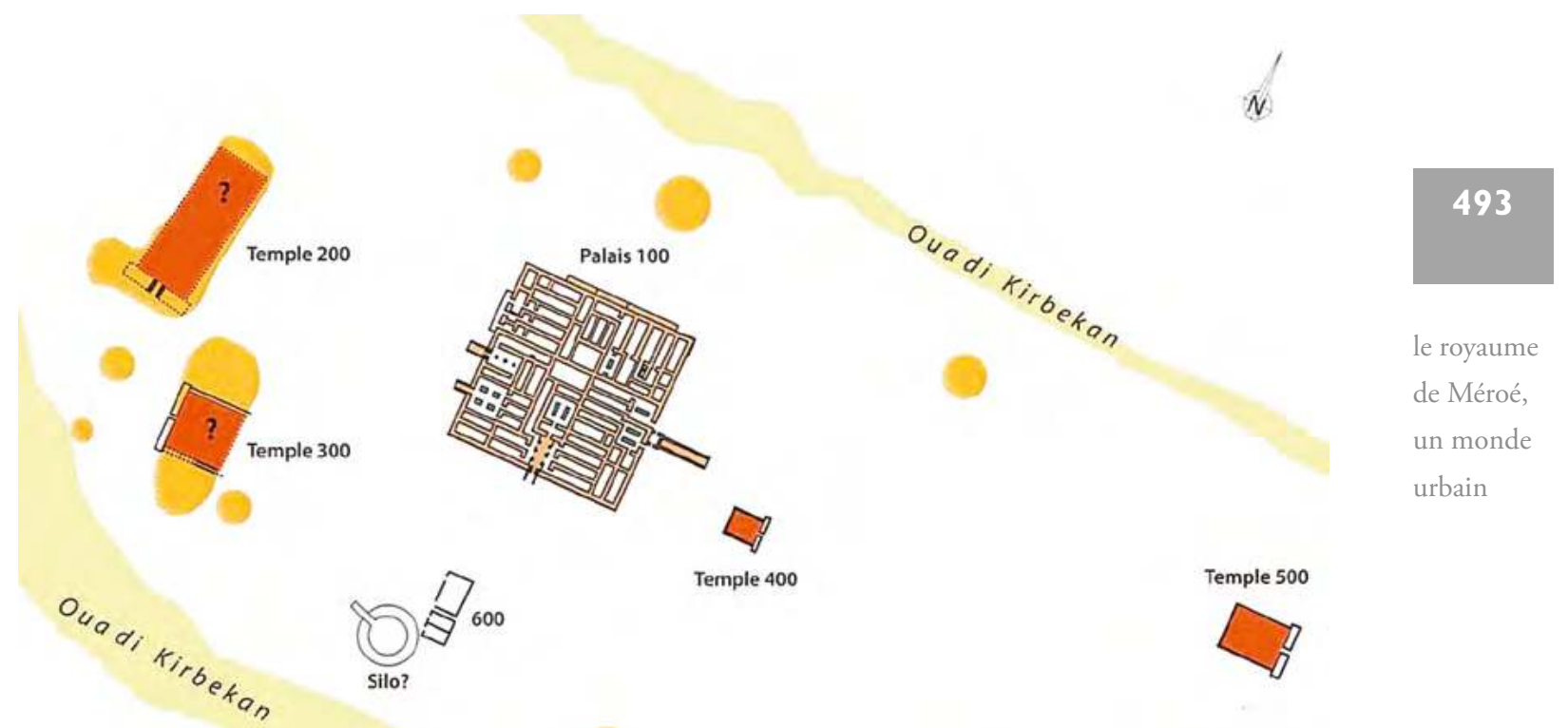

Temple 400

Temple 500

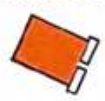

le royaume de Méroé, un monde urbain

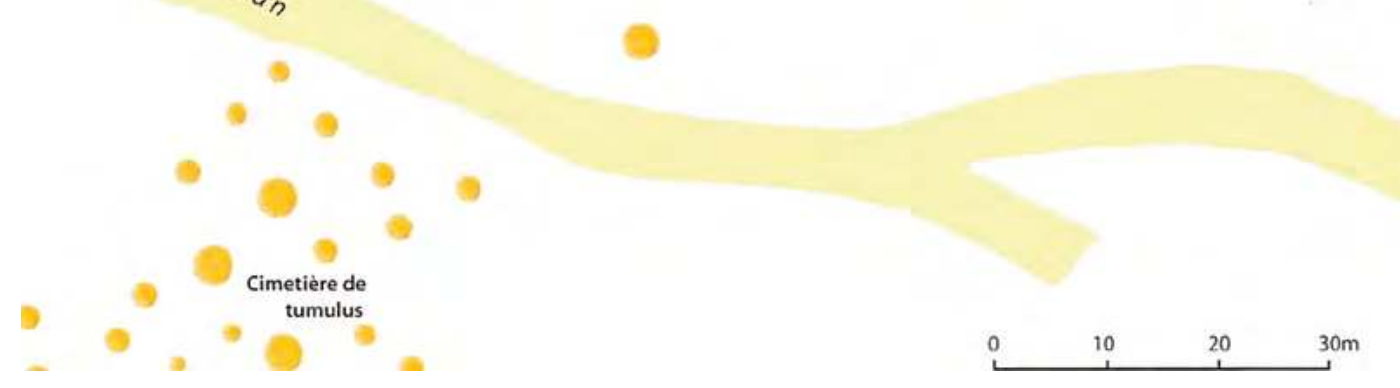

Figure 10: Palais et temples à Ouad ben Naga (d'après Baud 2010, fig. 288). 
du dromos du Sérapéum de Memphis ${ }^{124}$, daté du règne de Ptolémée Irr. Le lion est associé à la figure de l'enfant Dionysos ${ }^{125}$ et, de fait, établit une relation entre les figures du lion, d'Osiris et du roi ${ }^{126}$.

Il demeure cependant une différence importante entre les parallèles proposés par la mission italienne, et plus particulièrement le comparatif avec le M195 de Méroé. En effet, l'eau rituelle est destinée à être conservée dans le bassin du sanctuaire de Méroé, tandis que B 200 favorise un écoulement hors de la structure. Ceci indique une fonction divergente, connexe à la crue et aux sources du Nil ${ }^{127}$. La position du B 2200 dans l'axe $\mathrm{du}$ palais B1500 induit ainsi une relation entre les deux édifices, surtout si l'on considère la fonction potentielle du palais de Natakamani associé au rituel de renouvellement royal lors de la fête du Nouvel $\mathrm{An}^{128}$. Il est d'ailleurs notable qu'un seul et unique bassin fut découvert au sein du M194-195 ${ }^{129}$, mais des bassins supplémentaires de plus petites dimensions ont été découverts au sein du palais M $295^{130}$, dans le vaste complexe M998 ${ }^{131}$ et en M621. L'observatoire antérieur au M950 contenait lui-même des bassins et citernes associés à la crue nilotique ${ }^{132}$. L'importance du Nil est d'ailleurs constante en tant qu'élément structurant de la géographie cognitive. Sa direction constitue le critère fondamental, et plus spécifiquement le sens de son écoulement en amont-aval et sa direction, plutôt que son orientation nord ou sud ${ }^{133}$, celle-ci pouvant être inversée dans les méandres et les grandes boucles du Nil. Ceci explique que le groupe Sanam Abou Dôm-Barkal (équivalent de Karnak) et sa nécropole méridionale, Nouri (équivalent de Thèbes ouest), soient en réalité à "l'ouest», considérant le cours local du fleuve ${ }^{134}$.

histoire et

La relation temple-palais est également renforcée par la précivilisations sence de magasins-greniers indépendants, comme M740 de Méroé situé dans le temenos du temple et contemporain du palais $\mathrm{M} 75 \mathrm{O}^{135}$. La structure circulaire du kôm F de Ouad ben Naga peut avoir eu une fonction similaire, étant donné la présence d'une série de magasins allongés et étroits en contrebas du kôm et au pied du silo proche du palais 100 (figure 10) ${ }^{136}$. Il est probable qu'une structure de fonction similaire soit présente dans toutes les villes d'importance, bien qu'elles ne soient pas toujours bien conservées, tout comme en Égypte. En effet, la présence d'un grenier indépendant dans la ville méroïtique, à proximité d'un temple et d'un palais, est d'une importance significative car elle reflète une politique économique déterminée idéologiquement, rendant l'analogie avec l'Égypte pharaonique particulièrement séduisante, où le grenier constitue un élément clé dans la gestion des ressources du royaume, en parallèle aux magasins palatiaux ${ }^{137}$.

La structure circulaire de Ouad ben Naga est située sur la bordure méridionale du site, à quelques mètres de la branche sud du Ouadi Kirbekan ${ }^{138}$. Le kôm qui l'abrite était recouvert de caissons de briques cuites. 
Le bâtiment, circulaire (figure 11), est envisagé par les fouilleurs comme une sorte de tholos ${ }^{139}$ et posséde des murs épais de 3,70 m parementés sur la face externe de briques cuites recouvertes d'enduit blanc. Le cœur de la maçonnerie est en revanche en brique crue et le parement interne en brique cuite. Le revêtement de la paroi interne n'est cependant pas uniformément interprété, puisqu'il est tour à tour décrit comme absent ${ }^{140}$, ou enduit de boue limoneuse ${ }^{141}$, ou encore badigeonné à la chaux ${ }^{142}$.

Le diamètre interne du bâtiment est de $12,70 \mathrm{~m}^{143}$, avec une élévation atteignant en certains endroits $5 \mathrm{~m}^{144}$. Le diamètre externe est de $20 \mathrm{~m}$. L'épaisseur des murs tend à envisager une couverture par coupole ou une toiture conique en encorbellement ${ }^{145}$, ce qui en fait un édifice unique en l'état actuel des connaissances de la période méroïtique ${ }^{146}$. L'entrée est accessible par une rampe ${ }^{147}$ fondée sur un escalier antérieur ${ }^{148}$ qui s'étend sur la façade occidentale du bâtiment (figure 12). Haute de $2 \mathrm{~m}$ selon les fouilleurs, elle ouvre sur un passage initialement couvert aménagé dans la maçonnerie. Le passage menait à un double escalier adossé à la paroi interne de la structure et encadrant l'embrasure du passage de part et d'autre ${ }^{149}$. L'escalier descendait jusqu'au niveau du sol du bâtiment ${ }^{150}$ qui est divisé en compartiments par de fines cloisons en brique crue ${ }^{151}$.

L'orientation de la rampe d'accès vers le temple d'Isis et non vers le palais incite à interpréter le monument en tant qu'annexe de temple ${ }^{152}$ ou élément de mammisi ou de typhonium ${ }^{153}$. Cette impression est renforcée par la série de magasins rectangulaires ${ }^{154}$ dégagés à la base du monument ${ }^{155}$ qui, selon J.Vercoutter, rappellent les magasins de temples égyptiens ${ }^{156}$. Ces magasins sont construits en brique crue et contenaient de la vaisselle domestique assez grossière ${ }^{157}$. F. Hinkel les met en rapport avec le temple OвN $300{ }^{158}$, mais fait également le lien avec les vestiges de 12 réservoirs d'alimentation dégagés par Vercoutter en 1976 dans Овл $600{ }^{159}$.

J.Vercoutter signale également une influence indienne possible sur la culture méroïtique, suggèrant une interprétation de ce silo comme un temple-tour d'inspiration indienne ${ }^{160}$. A. Hakem avait déjà indiqué en 1988 le côté hasardeux d'une telle comparaison ${ }^{161}$, uniquement basée sur l'aspect circulaire de la structure qui tranche avec la régularité et la cohérence de l'architecture sacrée. Le plan circulaire est pourtant connu des bâtisseurs soudanais ${ }^{162}$, et le site de Kerma permet d'observer la qualité des techniques de construction employées pour ce type d'édifice ${ }^{163}$. Ajoutons que les plans circulaires sont bien maitrisés ${ }^{164}$, dans l'architecture tant funéraire que domestique ${ }^{165}$, et ce également en Égypte ${ }^{166}$. La sphère d'influence peut donc se limiter à l'Égypte hellénistique et romaine, du moins pour le plan du bâtiment ${ }^{167}$. 


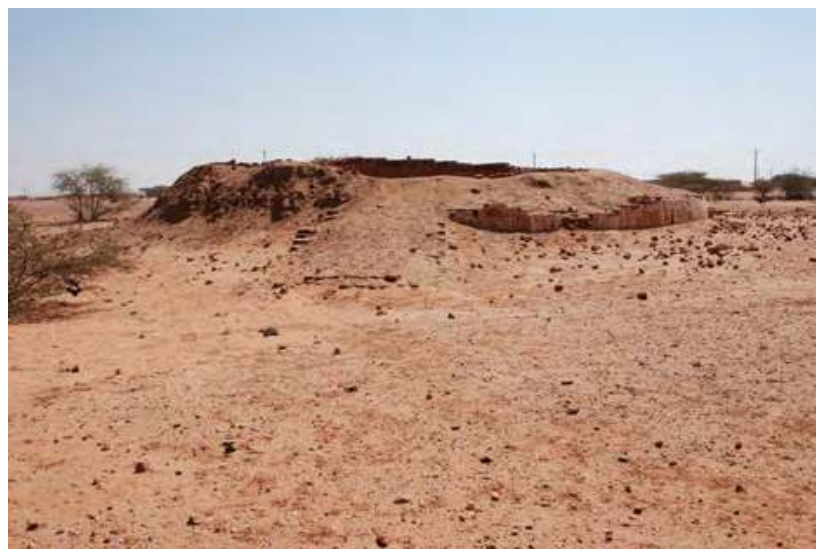

Figure 11: Vue générale du silo Ouad ben Naga 51.

le Soudan

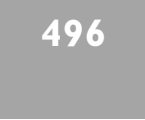

histoire et civilisations

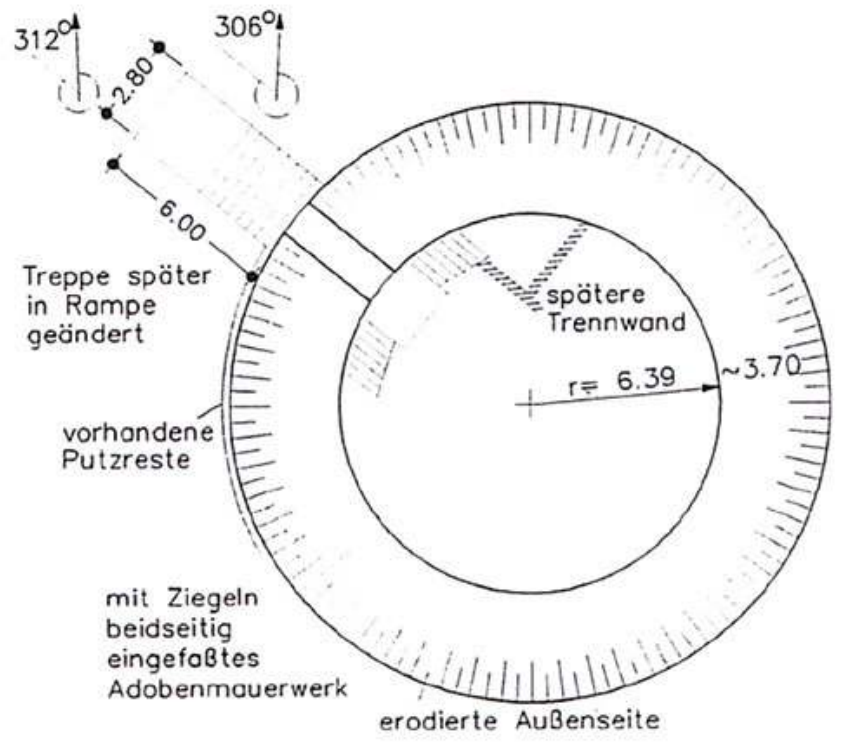

GRUNDRISS, noch einem Aufma $B$ von F. W. H., 1983

F. W. Hinkel. 1997

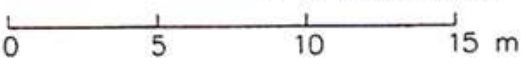

Figure 12: Plan du silo circulaire de Ouad Ben Naga 51

(d'après Hinkel et Sievertsen 2002, fig. IX.73). 
La courte note de $S$. E. Nur ${ }^{168}$ suggère que l'édifice correspond plutôt à une sorte de grenier communautaire et confirme l'hypothèse d'une couverture en dôme ${ }^{169}$. L'importante épaisseur du parement externe indique selon lui une fonction de protection hydraulique, bien que pour lui l'intérieur de la structure ne soit pas également enduit. Il interprète également la rampe externe comme un accès dédié aux chariots tirés par les bêtes afin d'en déverser le contenu dans le grenier tout en les maintenant à une hauteur raisonnable. Cette idée justifie ainsi le double escalier interne, qui aurait permis au personnel de descendre au fond du silo. A. Hakem supporte cette interprétation ${ }^{170}$ en s'appuyant sur les modèles égyptiens du Nouvel Empire, notamment à Amarna ${ }^{171}$, à Medinet Habou ${ }^{172}$ et à Sésébi ${ }^{173}$. Ce silo permet également, à l'échelle du site, d'envisager la ville de Ouad Ben Naga comme une cité stratégique située au pied du Ouadi Awatib et ouvrant sur le Boutana occidental ${ }^{174}$. Une datation contemporaine du couple Natakamani-Amanitoré est pour l'instant la seule suggestion avancée ${ }^{175}$.

La probable couverture "en dôme» de la structure est également intéressante. En effet, les voûtes fermées et les coupoles constituent une catégorie de couvrements en brique crue très rare dans les contextes méroïtiques étudiés. À l'exception du cas particulier des silos de sous-sol ${ }^{176}$, on ne les rencontre que dans des espaces dont la portée dépassait les limites induites par la solution de la voûte nubienne. La structure de Ouad ben Naga 51 est de ce fait unique, de par son plan circulaire ${ }^{177}$ mais surtout en raison de son couvrement probable en "dôme» ${ }^{178}$. Ainsi que nous l'avons présenté dans le descriptif précédent, et faute d'équivalents locaux ${ }^{179}$, les plus proches parallèles envisagés par les fouilleurs sont en Égypte, et plus particulièrement les modèles de silo du Nouvel Empire ${ }^{180}$. Il nous semble cependant que ce «dôme» correspond en réalité à la technique de la coupole en encorbellement, bien connue de l'architecture égyptienne, en particulier dans des contextes de la Basse Époque qui en constituent sans doute les modèles d'origine ${ }^{181}$. La fonction des bâtiments serait également similaire ${ }^{182}$.

Un autre exemple significatif de l'association temple-palaisgrenier correspond à la structure M191 de Méroé ${ }^{183}$. Ce bâtiment, érigé sur le niveau de destruction d'une petite chapelle surmontant le sanctuaire de l'eau M194-195 ${ }^{184}$, au sud du petit temple M291, est daté entre le premier et le second siècle de notre ère. Les niveaux antérieurs au magasin ont été nivelés et reposent pour partie sur un pan du mur oriental de l'enceinte de la cité royale $^{185}$. Le plan de l'édifice, mesurant $80 \times 40 \mathrm{~m}$, consiste en sept pièces rectangulaires distribuées par un couloir allongé et étroit ${ }^{186}$, ce qui indique que le processus de redistribution était encore en place à la période méroïtique tardive, et probablement en connexion avec le groupe temple-palais ${ }^{187}$. Le matériel issu des couches du M191, bien qu'extrêmement brassé, contenait 
des fragments de tuiles faïencées, certainement destinées à la décoration pariétale ${ }^{188}$, et du matériel cultuel. Notons également la présence d'un chapiteau en grès mal conservé, stuqué et peint, dont la description n'est malheureusement pas disponible, l'objet étant simplement mentionné ${ }^{189}$.

Le grand nombre de résidences royales contemporaines sur plusieurs sites méroïtiques peut s'expliquer par le principe de royauté ambulatoire ${ }^{190}$ formulé par L. Török ${ }^{191}$. Le principe s'accorde particulièrement bien avec une légitimation itinérante du pouvoir royal lors de cérémonies dans les grandes villes du royaume. Une fois le rituel du couronnement accompli à Napata ou Méroé, le roi entreprend une visite des provinces stratégiques afin d'affirmer son pouvoir dans les principaux centres urbains et affirme, à la mort de son prédécesseur, son autorité sur l'ensemble du territoire ${ }^{192}$. Bien que l'hypothèse soit séduisante et fonctionne parfaitement pour les grandes capitales, elle pose un problème de taille.

En effet, la présence récurrente de bâtiments palatiaux sur de nombreux sites méroïtiques impliquerait que chacun d'entre eux soit une ville royale, et une étape du couronnement. Cependant, la présence de plusieurs bâtiments palatiaux contemporains séparés d'à peine $30 \mathrm{~km}$ l'un de l'autre rend le principe de royauté ambulatoire improbable, tout du moins dans la région du Boutana central où le phénomène est particulièrement frappant ${ }^{193}$. Ainsi, la présence des palais de Ouad Ben Naga, de Mouweis et de Damboya près d'el-Hassa accrédite davantage l'idée de palais de gouverneurs locaux, habilités à relayer l'autorité royale, que celle d'édifices dédiés à la cérémonie du couronnement ${ }^{194}$.

histoire et civilisations

Cela tend à être confirmé par la relative pauvreté des moyens mis en œuvre, même s'il est vrai que l'état de conservation des vestiges peut fausser l'analyse. Par comparaison au palais B 1500 de Barkal, ou même au M75o de Méroé, les méthodes de construction mises en œuvre présentent des finitions moins léchées, notamment dans les appareillages. Le matériel découvert est à l'avenant, bien que le principe de récupération constante des Méroïtes et l'état très arasé des constructions aient facilité la disparition de matériel équivalent lors de la fouille ${ }^{195}$. Toutefois, le remplacement de la cour centrale à colonne par des puits de lumière centraux implique probablement un choix moins technique (on les retrouve dans l'architecture monumentale administrative) et, surtout, moins coûteux. Ceci, combiné à une maîtrise parfaite des différentes applications de l'adobe, forme un terreau idéal pour standardiser un modèle de plan particulièrement innovant, comme B1500 de Barkal, à moindres frais. Nous serions donc face à une multiplication des plans palatiaux commandités par les gouverneurs des provinces stratégiques et des centres de taxes, 
afin de s'aligner sur un modèle royal à l'apogée de sa puissance. Ajoutons que les distances concernées, entre 30 et $50 \mathrm{~km}$, sont franchissables en quelques jours pour une caravane, ce qui devait considérablement faciliter la communication et la gestion des denrées entre les différents secteurs sous contrôle étatique ${ }^{196}$. L'avantage est considérable dans une région comme le Boutana central, véritable grenier de l'Empire. La notion de royauté ambulatoire serait ainsi limitée aux grandes villes du royaume et serait complétée par une multiplication des plans palatiaux commandités par une classe élitaire sous contrôle étatique. Par ailleurs, nous ne serions pas surpris d'observer dans un futur proche une prolifération de la présence des palais lors de surveys ou de campagnes de fouilles extensives dans la région du Boutana, et même en dehors.

De fait, nous envisageons un schéma fonctionnel modulable, où le concept de palais est appliqué à la lettre dans les grandes capitales (B1500) et suivi dans ses grandes lignes dans les provinces majeures (Mouweis). Le palais est une sorte d'entité multitâche, pouvant à la fois être le théâtre de cérémonies rituelles (M 251-253) et remplir des fonctions résidentielles et de stockage, pas systématiquement reliées au culte (Ouad Ben Naga 100). Il peut également se spécialiser en fonction de l'évolution du paysage urbain (Barkal 100 après l'érection du B1500) ou constituer avant tout un relais économique et politique imitant les "grands palais» (Mouweis). Ceci n'est cependant applicable que lorsque nous pouvons détourer des caractéristiques planimétriques communes. En l'état actuel, ce n'est possible que pour la période comprise entre le premier siècle avant J.-C. et le premier siècle de notre ère. Ces considérations découlant des données issues de fouilles, le constat ici présenté ne se veut qu'une première étape vers une meilleure compréhension de la Nubie palatiale. Les fouilles récentes, telles que celles de Mouweis ou el-Hassa, pourront ainsi apporter de nouvelles données archéologiques et permettront une meilleure appréhension de l'urbanisme méroïtique - 
W.
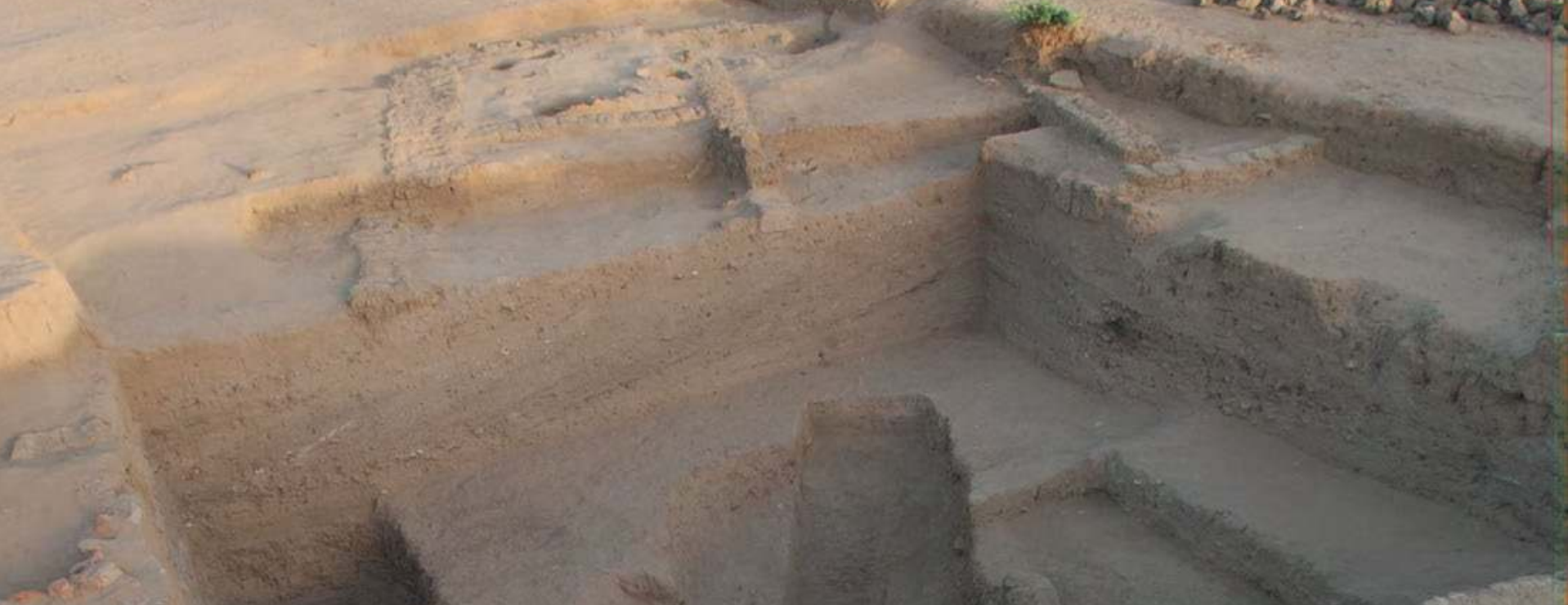

?
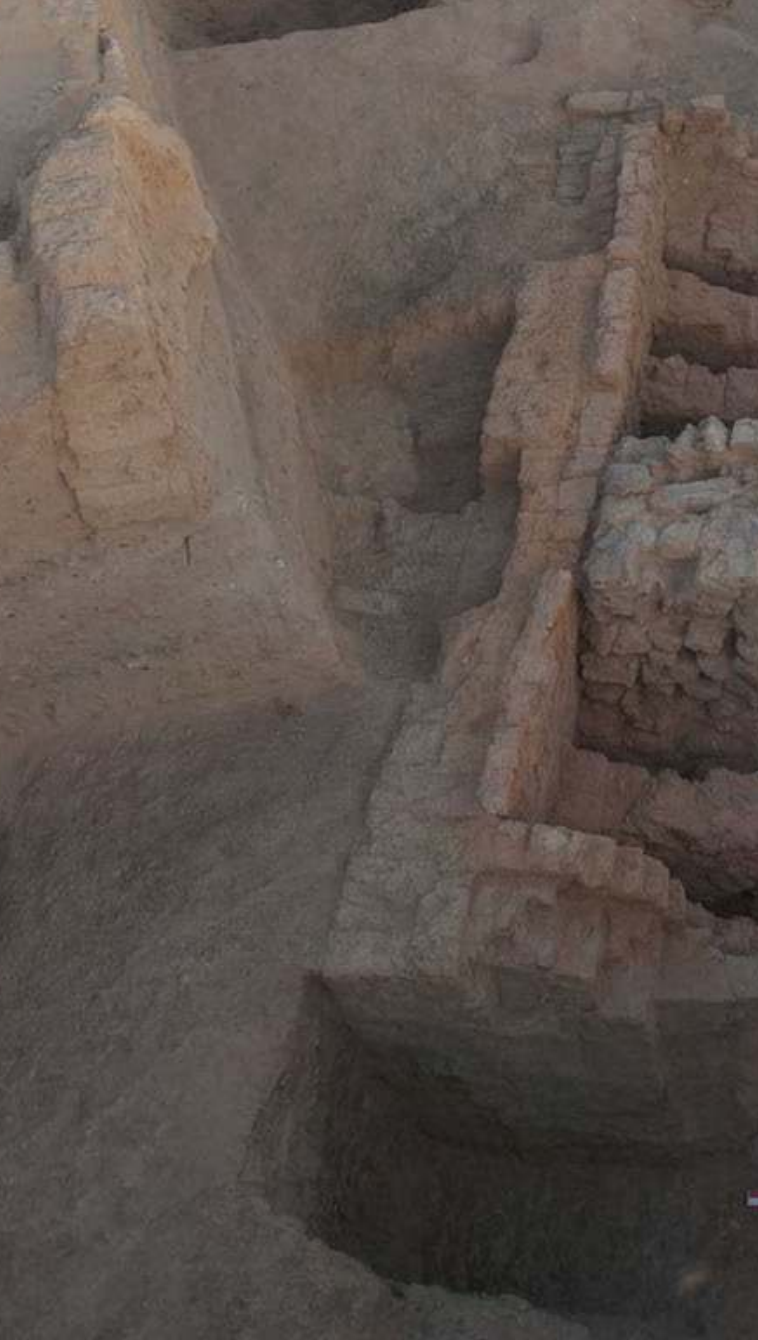

Mouweis, four rectangulaire $\mathrm{F}_{40}$, secteur $\mathrm{Ka}$, 2010.
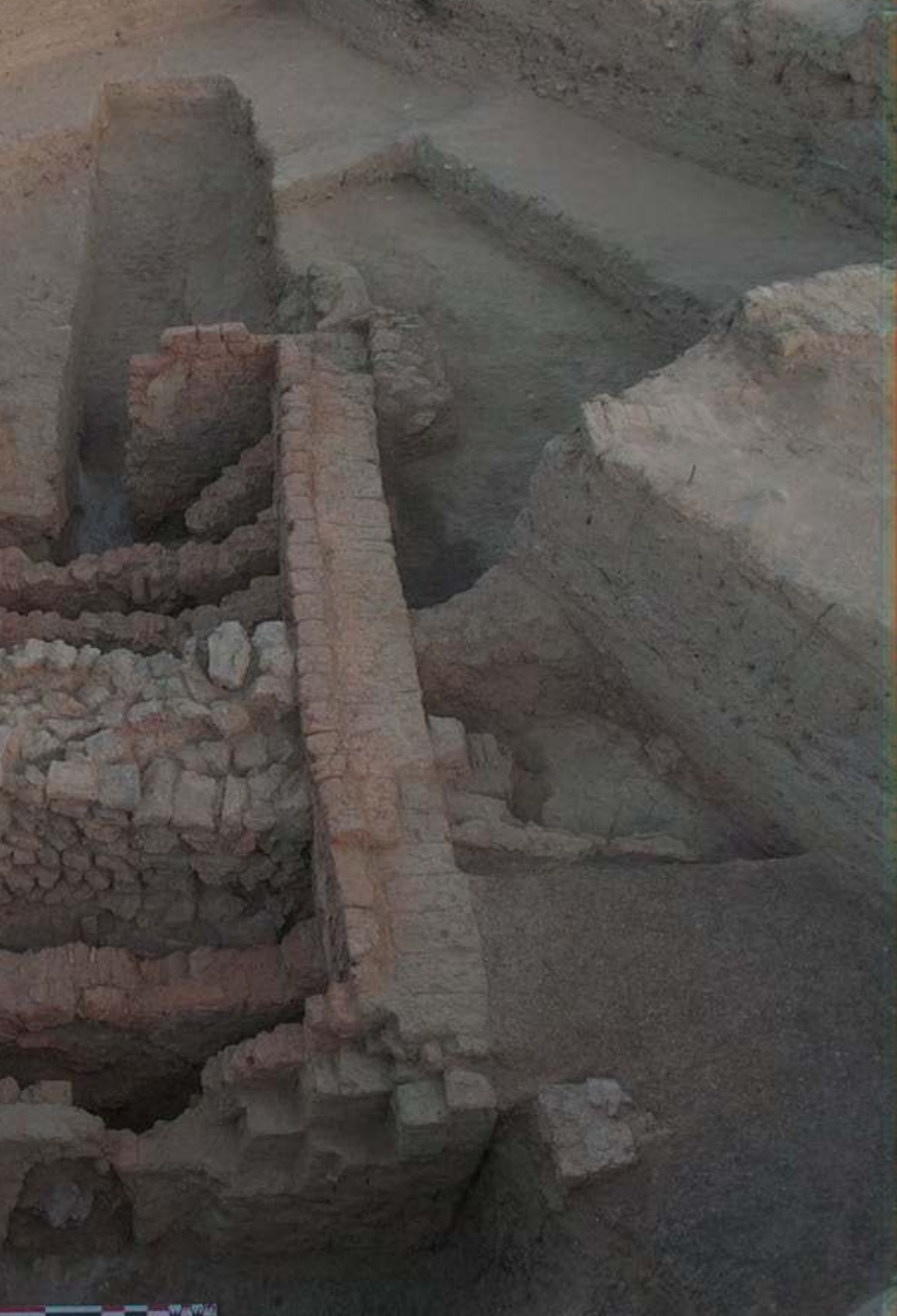


\section{notes}

1 Hinkel et Sievertsen 2002, p. 70 ;

Maillot 2014, 2013a et b.

2 Shinnie et Bradley 1980, p. 93.

3 Baud 2011, p. 343.

4 Vercoutter 1962, p. 279-28o, fig. 9-10;

Vrtal 2014a, p. 164-177.

5 Donadoni 1993, p. 104, 107.

6 Baud 2011, p. 343; Maillot 2014, p. 786.

7 Hinkel 1984, p. 247.

8 Barberini 2010, p. 169.

9 Voir également le bâtiment surélevé de Kôm el-Abd: Kemp 1977, p. 71-82. Ce "palais» est une structure à plateforme de $40 \times 45 \mathrm{~m}$, au sol élevé de $3,75 \mathrm{~m}$, accessible par une rampe de façade;cetteplateformen'estqu'unepartie d'un ensemble plus grand ceinturé par une muraille. Si B. Kemp considère que le petit nombre de murs de refend fait penser à des structures supérieures légères, M. Bietak y voit au contraire un ensemble élaboré, de type grande villa amarnienne avec salles à colonnes, même s'il manque les habituels murs de fondation.

Deux salles du trône sont probables, dont la principale à 6 colonnes possède un mur ouest très puissant, Bietak 2005, p. 131-168.

10 Barberini 2010, p. 170-173.

11 Barberini 2010, fig. 8.

12 Barberini 2010, p. 172.

13 Vitruve IV, 7, 3.

14 Du moins, même pour les classes sociales intermédiaires, les populations les plus pauvres ne pouvant pas financer une maison à péristyle, qui nécessite une surface minimale: Rumscheid 1998, p. 93-95 et 141-147; Sewell 2010, p. 106-108, 122-127.

15 Sewell 2010, p. 119-121.

16 Pline l'Ancien, $H_{N}$ VI, 184-187; FHN III, $\mathrm{n}^{\circ} 206$.

17 Anderson et Ahmed 2008, p. 40-46; Bumbaugh 2011, p. 66-69.

18 Adams 1977, p. 374; Millet 1964, p. 7-14.

19 McKenzie 2007, p. 145 et fig. 254.

20 Barberini 2010, p. 170-173.

21 Török 2002, p. 19.

22 Roccati 2014, p. 295

23 Baud 2011, p. 341-343; Maillot 2013a et b.
24 Hinkel et Sievertsen 2002, p. 67-70.

25 Voir le chapiteau ionique du в 2400 , pouvant indiquer une cour péristyle à chapiteau ionique au cœur de l'édifice. Il s'agit du seul exemple connu à ce jour dans l'architecture méroïtique: Barberini 2010, p. 170-173.

26 Roccati 2008, p. 251; Roccati 2014, p. 296

27 Kendall 1991, p. 302-313.

28 Hinkel et Sievertsen 2002, p. 67-70; Baud 2011, p. 343.

29 Roccati 2008, p. 251.

30 Baud 2011, p. 354-355; Maillot 2014, p. 794-795.

31 Uphill 1972, p. 721-734.

32 Baud 2011, p. 352; Maillot 2014, p. 784-786.

33 Török 2002, p. 10-34

34 Uphill 1972, p. 724-727 et fig. I.

35 Lacovara 1996, p. 139-147.

36 O'Connor 1989, p. 73-87.

37 Ce qui n'est pas sans poser des problèmes majeurs, le palais de Malqata pouvant être relié au temple par une allée, dont il reste une portion encore visible à l'ouest de l'enclos principal du palais: Smith 1958, p. 160-172 et fig. 55 .

38 Török 1997a, p.114.

39 Hinkel et Sievertsen 2002, p. 99-100.

40 Török 1997a, p. 30.

41 O'Connor 1989, p. 72-84; Lacovara 2009, p. 84 et n. 5 .

42 Smith 1958, p. $160-172$ et fig. 55 .

43 Kemp 1991, fig. 74.

44 Török 1997a, p. 181-187.

45 Hinkel et Sievertsen 2002, p. 123; Grzymski 2005, p. 52.

46 Török 1997a, p. 182.

47 Bonnet 1994, p. 41-48 et particulièrement 43 et 46-47; Bonnet 1999, p. 486 ;

Török 2002, p. 19-34.

48 Dorner 1996, p. 69-71.

49 O'Connor 1989, p. 73-87.

50 Török 2002, p. 48.

51 Török 2002, p. 48

52 Török 1997b, p. 220-229 et 249

53 Macadam 1949, p. 15, 62; $F_{H N}$ II, n ${ }^{\circ}$ 7; Welsby 1996, p. 34.

54 Voir stèle de Nastasen, an 8, musée égyptien de Berlin 2268: FHN II, n 84 ; Török 1997b, p. 217 et n. 115 .

55 Török 1997b, p. 221-223.

56 Wenig 1992, p. 137-140.

\section{1}

le royaume

de Méroé,

un monde

urbain 
57 Pour le modèle égyptien, voir Goyon 1972, p. 19.

58 Voir la stèle de couronnement d'Anlamani à Kawa: Macadam 1949, p. 44-50, pl.15; FHN I, n 34 .

59 Hinkel et Sievertsen 2002, p. 112.

60 Török 1997b, p. 378 et n. 206.

61 Wenig 1992, p. 137-140. L'auteur met à part la ville de Napata, faisant de Méroé un lieu d'investiture symbolique, de même importance que les autres étapes nécessaires à l'intronisation, comme Kawa ou Tabo. Ce point est par la suite contesté par L. Török, qui rejette l'idée même d'investiture symbolique, toutes ces villes constituant chacune une véritable étape de couronnement, avec Méroé en point d'orgue: Török 2009, p. 342 et n.16o. Nous penchons en faveur de L. Török, pour une raison simple: le couronnement est avant tout un acte politique (perspective majeure dont s'est trop éloigné D. O'Connor, et que H. Goedicke avait particulièrement bien relevée: Goedicke 1998, p. 200-201), et considérant l'importance de Méroé durant cette période, la charge

\section{2}

histoire et

civilisations propagandiste de l'événement est de facto plus importante à Méroé, du moins en l'état actuel des connaissances.

62 Il semble par ailleurs que la ville de Méroé soit déjà d'une importance considérable dès la $\mathrm{XXV}^{\mathrm{e}}$ dynastie:

Wenig 1992, p. 137-140.

63 Baud 2010b, p. 55.

64 Wenig 1992, p. 137-140.

65 Welsby 1996, p. 148-151.

66 Török 1997b, p. 518.

67 Bonnet 1994, p. 41-48. Voir notamment le parallèle entre la relation temple-résidence palatiale entre Tabo et Doukki Gel : p. 43, 46-47.

Török 2002, p. 19-34.

68 O'Connor 1989, p. 84-85.

69 Lacovara 2009, p. 84.

70 Hinkel et Sievertsen 2002, p. 99-100.

71 Kendall 1991, p. 302-313.

72 Bonnet-Valbelle 2004a, p. 158-159 et n. 174-175. Voir notamment la référence à l'ostracon de Deir el-Medineh 1072 et plus particulièrement les lignes 4 à 6 . L'ostracon évoque:

«l'eau dont l'Amon est sorti dans le pays de Kouch ".

Voir également le papyrus Boulaq 6 , viII, 7-8 qui déclare, à propos d'Amon: "Je ne parlerai pas de cette venue que tu as faite de Nubie tard le soir, Isteresek» (voir note 175). Le dernier terme pourrait être la transcription égyptienne d'une expression nubienne comprenant le nom d'un dieu bélier nubien, assimilé à Amon au début de la XVIII ${ }^{\text {e }}$ dynastie, le même papyrus déclarant au recto, II, 4-5, qu' "Heregen est un nom d'Amon" (voir note 176).

73 Török 2002, p. 19-34.

74 Török 1992, p. 16-17.

75 Török 1992, p. 18 et n. 54.

76 Török 2002, p. 368.

77 Török 2002, p. 19.

78 Ahmed et Anderson 2000, p. 17-31; Ahmed et Anderson 2005, p. 10-27.

79 Lenoble et Rondot 2003, p. 101-115; Rondot 2006, p. 41-47.

80 Baud 2011, p. 352-353.

81 Török 2002, p. 20. Excepté le cas du palais de Natakamani?

82 Bonnet-Valbelle 2004a, p. 120-125; Török 2002, p. 21.

83 Török 2002, p. 21 et n. 77.

84 Török 2002, p. 22

85 Török 2002, p. 40-41

86 L'interprétation des niveaux antérieurs au M 950 en tant qu'observatoire est suivie par L. Török: Török 2002, p. 29 et n. 116.

87 Török 2002, p. 24.

88 Baud 2010b, p. 61-64 et fig. 57.

89 Baud 2014, p. 765.

90 Baud 2014, p. 769.

91 Baud 2010d, p. 217 et fig. 281-282.

92 Baud 2010d, p. 218 et fig. 284.

93 Baud 2014, p. 771.

94 Baud 2010d, p. 216 et fig. 279; Baud 2014, p. 781.

95 Baud 2014, p. 775 et pl. 10.

96 Baud 2014, p. 773 et fig. 6.

97 Baud 2014, p. 773.

98 Baud 2014, p. 781.

99 Maillot 2014, p. 785-786 et pl.1; Maillot 2015, à paraître.

100 Baud 2014, p. 769. Également à Naga, Méroé et Ouad Ben Naga; au nord, au Gébel Barkal et à Amara, voir FHN III, p. 896-904; Török 2002, p. 226-227. On notera également 
les données provenant du temple d'Amon à Dangeil: Ahmed and Anderson 2007, p.31-32. L'examen des blocs du temple de Saï confirme également le programme en Basse-Nubie: Francigny 2008 et 2011, p. 404 n. 1.

101 Baud 2014, p. 771.

102 Maillot 2014, p. 793.

103 Lenoble 2009, p. 59-66.

104 Baud 2010c, p. 93-94.

105 Török 2002, p. 33.

106 Török 2002, p. 31.

107 Török 2002, p. 34-40.

108 Török 2002, p. 26: «a remarkable mix of coordination and independence in the location of its sanctuaries ".

109 Török 2002, p. 28.

110 Török 2002, p.30 et n. 123.

111 Török 2002, p. 187.

112 Török 1997a, p. 63-90.

113 Vlach 1984, p. 573-576.

114 Török 1997a, p. 235-241.

115 Török 2002, p. 29.

116 Chassinat 1966, p. 809-823;

Ciampini 2014, p. 695-697.

Pour alimenter la comparaison, notons le décret sacerdotal en l'honneur de Ptolémée II Évergète mentionnant la remontée d'Osiris depuis Héracleion jusqu'au temple d'Osiris à Canope. Les recoupages par prospection sous-marine ont révélé, parmi deux naos, une cuve aménagée de deux perforations. Cette cuve était destinée à héberger une figurine d'Osiris en argile, qui était ensuite séchée et transportée dans la nécropole de Canope: Yoyotte 2006, p. 130-131. L'usage habituel en Thébaïde depuis Thoutmosis III associe d'ailleurs un local consacré à Osiris en parallèle au temple du dieu majeur, comme à Hibis, Edfou et Dendérah: Yoyotte 2010, p. 37.

117 Robichon, Barguet et Leclant 1954, pl. 61; Traunecker 2010, p. 170-176 et n. 95. L'association de la purification d'Osiris, par l'intermédiaire de Hâpy, avec le rituel de couronnement royal est ici particulièrement adéquate.

118 Chassinat 1966, p. 809-823; Ciampini 2014, p. 695-697. L'analyse en cours de cette structure en connexion avec le palais в 1500 par E. Ciampini constituera certainement un marqueur fondamental de la compréhension des palais méroïtiques et de leur symbolique.

119 Vlach 1984, p. 574; Traunecker 2010, p. 170-171. Notons d'ailleurs que l'hymne 23 de la façade de la chapelle d'Osiris à Karnak est également attesté à Musawwarat es-Sofra, inscription 16: Hintze 1963, pl. xva, blocs 503 à 506 et inscription 17: Hintze 1962, pl.xvb, blocs 525, 529 et $531 . \mathrm{Cl}$. Traunecker associe d'ailleurs le dieu Sébioumeker à Osiris, dans sa fonction de dieu-fils : Traunecker 2010, p. 165 en complément de sa fonction créatrice: Hintze 1963, p. 33 .

120 Török 1997a, p.76.

121 Hibbs 1985, p. 153.

122 Vlach 1984, p. 575. Notons également la récurrence du motif de la gargouille dans les contextes rituels égyptiens et méroïtiques, que ce soit dans les temples de Dendérah et d'Edfou ou dans les tables à libation dédiées au culte de l'inondation: Hibbs 1985 , p. 153 ; Török 1997a, p. 76.

123 Török 1997a, p.76.

124 Fraser 1972, p. 206-253.

125 Török 1997a, p. 76.

126 Sauneron 1964, p. 56; voir également Fitzenreiter 2014, p. 111-128 et Yellin 2014, p. 395-404.

127 Toujours en nous fondant sur la tradition égyptienne, se pourrait-il que les deux bassins renvoient aux deux grottes protégées par le dieu Khnoum, maître des inondations? : Pinch 2004, p. 154. L'association avec Khnoum en tant que gardien des portes de l'inondation mais également en tant que dieu «façonneur du corps royal» sur son tour de potier serait particulièrement adaptée. Ajoutons que Khnoum est également célébré au premier millénaire et à la période romaine au temple d'Esna en tant que créateur et animateur des corps physiques des dieux représentés en modèles réduits de statuettes en argile. Nous renvoyons à la note 116 et plus particulièrement à la petite figurine d'Osiris en argile placée dans la cuve à double perforation retrouvée par prospection sous-marine et destinée 
à un transfert vers la nécropole de Canope. Khnoum est par ailleurs régulièrement identifié à l'âme d'Osiris en tant que dieu créateur: Pinch 2004, p. 154. E. Ciampini semble également suggérer une telle piste: Ciampini 2014, p. 695 et n. 7 .

Ciampini 2014, p. 695-697.

\section{4}

histoire et

civilisations

Hinkel et Sievertsen 2002, p. 76

Vercoutter 1962, p. 274;
Török 1997a, p. 63-65.

Török 1997a, p. 122 et pl.145.

Török 1997a, p. 229.

Török 1997a, p.162 et pl.145.

Török 2002, p. 15.

Török 2002, p. 34-39.

Török 1997b, p. 518 .

Vercoutter 1962, p. 275;

Vrtal 2014b, p. 152-163.

Török 2010, p. 165-166.

Vercoutter 1962, p. 273-275,

pl. Xvirib et fig. 2 .

Vercoutter 1962, p. 274.

Vercoutter 1962, p. 274.

Hinkel et Sievertsen 2002, p. 76

Edwards 1996, p. 27.

et fig. IX. 73; Vrtal 2014b, p. 152-163.

Vercoutter 1962, p. 274

Ali Hakem 1988, p. 325 ;

Hinkel et Sievertsen 2002, p. 76.

Ali Hakem 1988, p. 325.

Vercoutter 1962, p. 274.

Hinkel et Sievertsen 2002, p. 76.

Ali Hakem 1988, p. 324.

Vercoutter 1962, p. 274

Ali Hakem 1988, p. 324.

Hinkel et Sievertsen 2002, p. 76 et fig. IX. 72 .

Vercoutter 1962, p. 275.

Vercoutter 1962, fig. $2 \mathrm{n}^{\circ} 4$.

Vercoutter 1962, p. 275.

Vercoutter 1962, p. 275.

Ali Hakem 1988, p. 324.

Hinkel et Sievertsen 2002, p. 76.

Hinkel 1984, p. 300.

Vercoutter 1962, p. 298.

Ali Hakem 1988, p. 325.

Ali Hakem 1988, p. 325.

Bonnet 2007, p. 183-246;

Bonnet et Valbelle 2010,

p. 44 et fig. 35 .

64 Voir le bol en bronze de Karanóg:

Woolley 1910, p. 59 et pl. 26-27.

Voir aussi la structure malheureusement

mal connue $\mathrm{B} 1000$ à Barkal, également circulaire et accessible par une rampe à l'angle nord-ouest du B 500 , et probablement reliée à ce temple:

Reisner 1917, p.125; Kendall 1994, p.141.

165

166

167

168

169

170

171

172

173

174

175

176

177
Ali Hakem 1988, p. 325.

Hertzog 1966; Spencer 2010, p. 15-24.

Ali Hakem 1988, p. 325.

Sadik en-Nur 1962, p. 26.

Ali Hakem 1988, p. 326.

Ali Hakem 1988, p.325.

Petrie 1894, p. 24.

Badawy 1966, p. 147.

Fairman 1938, p. 153.

Baud 2010e, p. 241-243

Hinkel et Sievertsen 2002, p. 76.

Hinkel 1984, p. 300.

Hinkel et Sievertsen 2002, p. 76.

Ce type de plan est toutefois bien connu pour le bâtisseur méroïte:

Ali Hakem 1988, p. 325.

Ali Hakem 1988, p. 326.

Hinkel 1984, p. 300-301.

Badawy 1966, p. 147.

Ces structures de Basse Époque sont également fondées sur caissons et comprennent des silos à encorbellement. Ainsi à Mendès : Wilson 1982, p. 5-8, pl. III, v, IX-2; à Toukh el-Qaramous: Edgar 1906, p. 207, fig. 2; à Kom Firin: N. Grimal, Adly, Arnaudiès 2008, p.191-192, fig. 12; à Bouto: Hartung-Ballet 2003, p. 211-215, fig. 5, pl.38-b, 38-c, 39-b.

Sadik en-Nur 1962, p. 26.

Török 1997a, p. 61-63.

Welsby 1996, p.130.

Török 1997a, p. 62.

Welsby 1996, p. 130 et fig. 55.1.

Török 1997a, p. 62.

Török 1997a, p. 63.

Garstang 1914, p. 17.

Török 1992, p. 111-126.

Török 2010, p. 165.

Török 2010, p. 166-170.

Török 2010, p.165-166.

Baud 2011, p. 355

et Maillot 2014, p. 795 .

Baud 2011, p. 352.

Bonnet 1999, p. 485 ;

Török 2010, p.165-166. 
bibliographie 
Adams W.Y. $\quad 1965$ - "Sudan Antiquities Service Excavations at Meinarti (1963-1964)», Kush 13, p. 148-176

1977 - Nubia: Corridor to Africa, Princeton.

Adams W.Y., Nordström H.A.

1963 - "The Archaeological Survey on the West Bank of the Nile:

Third Season (1961-1962)», Kush 11, p. 10-46.

Addison F. $\quad \mathbf{1 9 2 6}$ - "Ancient Sites near Nagaa», $S_{N R}$ 9, p. 56-58.

1949 - Jebel Moya, The Wellcome Excavations in the Sudan, vol. 2, Oxford. 1956 - "Second thoughts on Jebel Moya», Kush 4, p. 4-18.

Addison F., Dunham D.

Ahmed S. El-Din M.

1922 - «Alem, a Meroitic Site», SNR 5, p.39-46.

2010 - «Un siècle d'archéologie méroïtique», in Baud M. (dir.),

Méroé, un empire sur le Nil, musée du Louvre éditions, Officina Libraria, Paris-Milan.

Ahmed S. El-Din M., Anderson J.

2000 - «Prospections archéologiques et fouilles de sauvetage dans le voisinage du site de Dangeil (1997-1999)", Cripel 21, p.17-37. 2005 - «Le temple d'Amon à Dangeil (Soudan)», BSFE 162, p.10-27.

le Soudan 2006 - «Painted Plaster: A Glimpse into the Decorative Program Used in the Amun Temple at Dangeil, Sudan ", JSSEA 33 (Studies Millet II), 2006, p. 2-3.

2007 - "The "Throne Room" and Dais in the Amun Temple at Dangeil, Nile State Sudan ", in B. Gratien (éd.), Mélanges offerts à Francis Geus,

histoire et civilisations Cahiers de recherche de l'institut de papyrologie et d'égyptologie de Lille 26, p. 31-32.

2008 - "The Kushite Kiosk of Dangeil and Other Recent Discoveries ", SudNub 12, p. 40-46.

2010 - «Dangeil, à la découverte d'un nouveau temple d'Amon », in Méroé, un empire sur le Nil aux confins de multiples cultures, Dossiers d'Archéologie hors-série $\mathrm{n}^{\circ} 18$, p. 50-55.

Ali Hakem A. M. 1988 - Meroitic Architecture. A Background of an African Civilization, Khartoum.

Badawy A. $\quad 1966$ - A History of Egyptian Architecture, Berkeley, University of California Press.

Balfour-Paul H. G. 1952 - "Early Cultures on the Northern Blue Nile», $S_{N R} 33$, p. 202-215. Barberini S. $\quad 2010$ - "Gébel Barkal (season 1998): Reconstruction of the courtyard in B 1500 " in Between the Cataracts, PAM Supplement Series 2/2, Varsovie p. $169-180$.

Baud M. $\quad 2008$ - "The Meroitic Royal City of Muweis: first steps into an urban settlement of riverine Upper Nubia", SudNub 12, Londres, p. 52-63. 
2010 a - (dir.) Méroé, un empire sur le Nil, musée du Louvre éditions, Officina Libraria, Paris-Milan.

2010 b — «Les trois Méroé: la ville, la région, l'empire», in Méroé, un empire sur le Nil, musée du Louvre éditions, Officina Libraria, Paris-Milan, p. 52-64.

2010 c — « La force du modèle égyptien : l'exemple des reposoirs de barque sacrée», in Méroé, un empire sur le Nil, musée du Louvre éditions, Officina Libraria, Paris-Milan, p. 93-94.

2010 d - "Méroé, un monde urbain", in Méroé, un empire sur le Nil, musée du Louvre éditions, Officina Libraria, Paris-Milan, p. 211-224. 2010 e - «La maison du roi : le palais», in Méroé, un empire sur le Nil, musée du Louvre éditions, Officina Libraria, Paris-Milan, p. 241-243. 2011 - «Premières données sur le palais royal de Mouweis» in Hommages Lenoble, Puf, Sfdas \& Ifpo (Rondot, V., Alpi, F. and Villeneuve, F. éds.), p. 339-357.

2014 - "Downtown Muweis-A Progress Report (2007-2011)» in The Fourth Cataract and Beyond, Proceedings of the $12^{\text {th }}$ International Conference for Nubian Studies, Leuven, Paris, Walpole, p. 763-783.

Bietak M. 2005 - "Neue Paläste aus der 18. Dynastie», in Jánosi, P. éd., Structure and Significance. Thoughts on Ancient Egyptian Architecture, Vienne, p.131-168.

Bonnet C. $\quad 1994$ - $\quad$ Palais et temples dans la topographie urbaine.

Les exemples du Bassin de Kerma", $R d E 45$ (dédié à la mémoire de C. Maystre), p. 41-48.

1999 - "Aux origines des palais kouchites», in S. Wenig (éd.),

Studien zum antiken Sudan, Meroitica 15, Wiesbaden, p. 484-494.

2007 - «Les fouilles archéologiques de Kerma», Genova 55,

p. $183-246$.

Bonnet C., Ahmed S. El-Din M.

1999 - «Excavations at Dokki Gel», in D. A. Welsby (éd.)

Recent research in Kushite History and Archaeology. Proceeding

of the $8^{\text {th }}$ international conference for Meroitic studies, BMOP 131,

Londres, p. 251-256.

Bonnet C., Valbelle D.

2004 a - Le temple principal de la ville de Kerma et son quartier religieux, Errance.

2004 b — «erma, Dokki Gel», in D. Welsby and J. Anderson (eds), Sudan Ancient Treasures. Londres, 109-112.

2010 - «Les antécédents: les royaumes de Kerma et de Napata», in Baud M. (dir.), Méroé, un empire sur le Nil, musée du Louvre éditions, Officina Libraria, Paris-Milan, p. 43-50. 
Bumbaugh S. $\quad 2011$ - "Meroitic Worship of Isis at Philae», in Egypt in its African Context, Proceedings of the conference held at the Manchester Museum, University of Manchester, 2-4 October 2009, BAR-Is 2204, p. 66-69.

Budge E.A.W. 1907 - The Egyptian Sudan: its History and Monuments, 2 vols., Londres. Burckhardt J. L. $\mathbf{1 8 1 3}$ - Travels in Nubia, Londres.

Cailliaud F. $\quad \mathbf{1 8 2 6}$ - Voyage à Méroé et au Fleuve Blanc au-delà du Fâzoql et dans le midi du royaume de Sennar, à Syouah et dans cinq autres oasis, fait dans les années 1819, 1820, 1821 et 1822, 4 vols. Textes et 2 vols. Planches, Paris.

Caminos R.A. 1968 - The Shrines and Rock Inscriptions of Ibrim, Londres.

Campagnoli P., Giorgi E.

2002 - "L'edilizia in argilla cruda e le techniche edilizie di Backhias. Note sul rilievo, l'interpretazione e la conservazione», REAC 4, p. 47-92.

Chassinat E. $\quad 1966$ - Le mystère d'Osiris au mois de Khoiak, Le Caire.

Chauvet M. $\quad \mathbf{1 9 8 9}$ - Frédéric Cailliaud. Les aventures d'un naturaliste en Égypte et au Soudan (1818-1822), Paris.

Ciampini E., Bąkowska-Czerner G.

2014 - "Meroitic Kingship and Water: The Case of Napata (B 2 200)» in The Fourth Cataract and Beyond, Proceedings of the $12^{\text {th }}$ International Conference for Nubian Studies, Leuven, Paris, Walpole, p. 695-702.

le Soudan

\section{8}

histoire et civilisations
Crawford O. G.S., Addison F.

1951 - Abu Geili and Saqadi \& Dar el Mek, The Wellcome Excavations in the Sudan, vol. 3, Oxford.

Crowfoot J. W. $\quad 1920$ - "Old Sites in the Butana», SNRec 3, p. 85-93.

Dewachter M. 1994 — «Les Voyageurs Français et la Nubie», in B. Gratien, F. Le Saout (éds.) Nubie, Les cultures antiques du Soudan, Lille, p. 35-43.

Donadoni S. 1993 - «Excavation of University of Rome at Natakamani Palace (Jebel Barkal)», Kush 16, p.101-115.

1994 - «Le palais de Natakamani au Gébel Barkal», La Nubie.

Dossiers d'Archéologie 196, p. 54-59.

Dorner J. 1996 - «Zur Lage des Palastes und des Hauttempels der Ramsesstadt», in Bietak M. (éd.), Haus und Palast im Alten Ägypten. Internationales Symposium 8 bis. 11. April in Kairo, Vienne, p. 69-71.

Dunham D. $1950-E l$ Kurru, RCK 1, Boston.

1955 - Nuri, RCK 2, Boston.

1957 - Royal Tombs at Meroe and Barkal, RCK 4, Boston.

1963 - The West and South Cemeteries at Meroe, RCK 5, Boston.

1970 - The Barkal Temples, Boston.

Edgar M. $\quad \mathbf{1 9 0 6}$ - "Report on an Excavation at Toukh el-Qaramous», AsAE 7, p. 205-212.

Edwards D.N. 1996 - The Archaeology of the Meroitic State: New Perspectives on its Social and Political Organisation, BAR-IS 640, Oxford. 
Edwards D.N. $\quad \mathbf{1 9 9 8}$ - Gabati. À Meroitic, post-Meroitic and Medieval Cemetery in Central Sudan, vol. 1, Londres.

2004 - The Nubian Past. An Archaeology of the Sudan, Londres.

Eide T. et al. 1994 - T. Eide, T. Hägg, R. H. Pierce \& L. Török, Fontes Historiae Nubiorum 1, Bergen.

1996 - T. Eide, T. Hägg, R. H. Pierce \& L. Török, Fontes Historiae Nubiorum 2, Bergen.

1998 - T. Eide, T. Hägg, R. H. Pierce \& L. Török, Fontes Historiae Nubiorum 3, Bergen.

Eisa K.A. $\quad 1999$ - "The White Nile Archaeological Survey», in D. A. Welsby (éd.) Recent research in Kushite History and Archaeology. Proceeding of the $8^{\text {th }}$ international conference for Meroitic studies, BMOP 131, Londres, p. 267-268.

El-Tayeb M., Kołosowska E.

2005 - «The Awlib Temple Complex: Kom B and its Pottery Assemblage ", Gamar 3, p.145-158.

Emery W. B. $\quad 1965-$ Egypt and Nubia, Londres.

Emery W. B., Kirwan L. P.

1935 - The Excavations and Survey between Wadi Es-Sebua and Adindan, 1929-1931, 2 vols., Le Caire.

Fairman H. W. 1938 - "Preliminary Report on the Excavations at Sesibi and Amarah West, Anglo-Egyptian Sudan", JEA 24, p. 151-156.

Ferlini G. $\quad \mathbf{1 8 3 7}$ - Nell'interno dell'Africa, Bologne.

Firth C.M. 1912 - The Archaeological Survey of Nubia. Report for 1908-1909, 2 vols., Le Caire.

1915 - The Archaeological Survey of Nubia. Report for 1909-1910, Le Caire. 1927 - The Archaeological Survey of Nubia. Report for 1910-1911, Le Caire.

Fitzenreiter M. 2014 - "Taharqa und Osiris, Fragmente einer Kapelle im Ägyptischen» in Ein Forscherleben zwischen den Welten. Zum 8o. Geburtstag von Steffen Wenig. Der Antike Sudan-MittSag Sonderheft (Festschrift Wenig), p. 111-128.

Francigny V. 2008 - "The Meroitic temple at Saï Island" in $11^{\text {th }}$ International Conference for Meroitic Studies, Vienne, September 2008, à paraître. 2010 a — «'île de Saï méroïtique», Dossiers d'archéologie, Hors-Série 18, p. 62-67.

2010 b - "The Meroitic Necropolises of Sai Island. Second Season at the Cemetery 8-B-5.A», Sudnub 14, p. 56-61.

2011 - "Le prince Arakakhataror", in Hommages Lenoble, Puf, Sfdas \& Ifpo (Rondot, V., Alpi, F. and Villeneuve, F. éds.), p. 403-411. 2015 - "The Meroitic Temple at Sai Island » in The Kushite World, Proceedings of the $11^{\text {th }}$ International Conference for Meroitic Studies, Vienne, 201-212. 
Fraser P. M. $\quad 1972-$ Ptolemaic Alexandria, Oxford.

Freier E., Grunert S.

1996 - Reise durch Ägypten. Nach Zeichnungen der Lepsius

Expedition 1842-1845, Berlin.

Freier E., Reinecke W.

1984 - Karl Richard Lepsius (1810-1884). Akten der Tagung anlässlich seines 100. Todestages, 10.-12.7.1984, Berlin.

Garstang J. 1911 - Meroe. The City of the Ethiopians, Oxford.

1914 - «Fourth Interim Report on the Excavations at Meroe

in Ethiopia", AaAliv 6, p.1-21.

1916 - J. Garstang, A. H. Sayce \& W. J. Phytian-Adams,

"Fifth Interim Report on the Excavations at Meroe in Ethiopia», AAALiv 7, p. 1-24.

Ginns A. $\quad 2007$ - $\quad$ Preliminary Report on the Second Season of Excavations Conducted on Mis Island (Aкsc)», SudNub 11, p. 20-25.

Goedicke H. 1998 - "Review of Ancient Egyptian Kingship, edited by D. O'Connor», in Jarce 35, p. 200-201.

Goyon J.-C. $\quad \mathbf{1 9 7 2}$ - La confirmation du pouvoir royal au Nouvel An (Brooklyn Museum Papyrus 47.218.50), Le Caire.

le Soudan Gradel C. 2009 - «L'université de Lille 3 au Soudan: une archéologie créatrice de patrimoine?» in O. Aboukorah et J.-G. Leturcq (dirs.), Pratiques du patrimoine en Égypte et au Soudan, Égypte, Monde Arabe n ${ }^{\circ}$ /6, p. 381-400.

Griffith F. LL. 1911 c - Meroitic Inscriptions. Part. I, Sôba to Dangêl, AsEg 19, Londres.

histoire et 1912 - Meroitic Inscriptions. Part. II, Napata to Philae and Miscellaneous,

civilisations AsEg 20, Londres.

1924 - "Oxford Excavations in Nubia», AAALiv 11, p. 141-180.

1925 - "Oxford Excavations in Nubia», AAALiv 12, p. 57-172.

Grimal N., Adly E., Arnaudiès A.

2008 - «Fouilles et travaux en Égypte et au Soudan, 2006-2008», Orientalia 77-3, p.186-288, pl. vII-XXXv.

Grzymski K. 2005 — "Meroe, the Capital of Kush: Old Problems and New Discoveries", SudNub 9, p. 47-58.

2006 - «Recent research at the palaces and temples of Meroe", in Between the Cataracts. Proceedings of the $11^{\text {th }}$ Conference for Nubian Studies, Warsaw University, 27 August-2 September 2006, PAM Supplement Series 2/1, Varsovie, p. 227-238. 2008 - «Excavations in Palace M 750S at Meroe», SudNub 12, Londres, p. 47-51.

Hartung H., Ballet P., et al. 2003 — «Tell el-Fara'i-Bouto », MDAIK 59, p. 199-267. 
Hertzog R. $\quad 1966$ - Punt, Abhandlungen des Deutschen Archaeologischen Institute Kairo, Gluckstadt.

Hewes G. W. $\quad 1964$ — «Gezira Dabarosa: Report of the University of Colorado Nubian Expedition (1962-63 Season)», Kush 12, p.174-187.

Hibbs V.A. $\quad \mathbf{1 9 8 5}$ - The Mendes Maze. A Libation Table for the Inundation of the Nile, Londres-New-York.

Hinkel F. W. $\quad \mathbf{1 9 8 4}$ — "Gedanken und Bemerkungen zum Thema "Meroitische Architektur" ", Meroitica 7, p. 290-309.

Hinkel F. W., Sievertsen U.

2002 - Die Royal City von Meroe und die repräsentative

Profanarchitektur in Kusch, The Archaeological Map of the Sudan Suppl. 4, Berlin.

Hintze F. 1959 - "Preliminary Report of the Butana Expédition 1958 »,

Kush 7, p. 170-196.

1962 - "Preliminary Report on the Excavations at Mousawwarat es Sofra 1960-1961», Kush 10, 170-202.

1963 - Die Inschriften des Löwentempels von Musawwarat es Sufra

(Abhandlungen der Deutschen Akademie der Wissenschaften zu Berlin, Klasse für Sprachen, Literatur und Kunst 1), Berlin, Akademie Verlag. 1968 - "Musawwarat es-Sufra: Vorbericht über Ausgrabungen des Instituts für Ägyptologie der Humbold-Universität zu Berlin, 1963 bis 1966 (vierte bis sechste kampagne), WZHU 5, p. 667-684.

Jacquet J. $\quad \mathbf{1 9 7 1}$ — «Remarques sur l'architecture domestique à l'époque méroïtique : documents recueillis sur les fouilles d'Ash-Shaukan", B̈̈BA 12, p. 121-131.

Jacquet-Gordon H., Bonnet Ch. 1999 - "Excavations at Tabo, Northern Province, Sudan», in D. A. Welsby (éd.) Recent research in Kushite History and Archaeology. Proceeding of the $8^{\text {th }}$ international conference for Meroitic studies, BMOP 131, Londres, p. 257-63.

Jacquet-Gordon H., Bonnet Ch., Jacquet J. 1969 - «Pnubs and the Temple of Tabo on Argo Island», JEA 55, p. 103-112.

Kemp B. J. $\quad 1977$ — «uilding of Amenophis III at Kôm el Abd», JEA 63, p. 71-82. 1991 - Ancient Egypt: Anatomy of a Civilization, Londres.

Kendall T. 1991 - "The Napatan Palace at Gebel Barkal, a first look at B 100 ", in W.V. Davies, éd., Egypt and Africa: Nubia from Prehistory to Islam, Londres, p. 302-313.

1994 - "A New Map of the Gebel Barkal Temples», Etnub II, p. 139-144. 1997 a - «es souverains de la montagne sacrée. Napata et la dynastie des Kouchites", Soudan. Royaumes sur le Nil, p.161-228. $\mathbf{1 9 9 7}$ b — «Excavations at Gebel Barkal», Kush 17, p. 320-354. 
Kendall T., Wolf P.

2007 - «xcavations in the Palace of Aspelta at Jebel Barkal,

March 2007", SudNub 11, p. 82-88.

2011 - «B6oo: A Temple of Thutmose IV at Jebel Barkal»

in Hommages Lenoble, Puf, Sfdas \& Ifpo (Rondot, V.,

Alpi, F. and Villeneuve, F. eds.), p. 237-26o.

Kirwan L. P. $\quad 1936$ - «Preliminary Report of the Oxford University Excavations at Kawa, 1935-1936», JEA 22, p. 199-212.

Klasens A. $\quad 1967$ — "Dutch Archaeological Mission to Nubia. The Excavations at Abu Simbel North 1962-1964", Campagne internationale de l'Unesco pour la sauvegarde des monuments de la Nubie. Fouilles en Nubie (1961-1963), Le Caire, p. 79-86.

Kröper K. 2006 - "Metamorphoses of the Amun Temple in Naga " in Acta Nubica-Proceedings of the X International Conference of Nubian Studies, Rome 9-14 September 2002, 287-296.

Lacovara P. $\quad 1996$ - «Deir-el Ballas and New Kingdom Royal Cities» in Bietak, M. éd. Haus und Palast im Alten Ägypten. Internationales Symposium 8 bis. 11. April in Kairo, Vienne, p. 139-147.

2009 - "The Development of the New Kingdom Royal Palace»

le Soudan

512 Leclant J.

histoire et civilisations
Lenoble $P$. in Gundlach R., Taylor J.H. (éds.) Egyptian Royal Residence, $4^{\text {th }}$ Symposium on Egyptian Royal Ideology, Harrassowitz Verlag, Wiesbaden, p. 83-110. 1962 - «Fouilles et Travaux en Égypte et au Soudan 1960-1961", Orientalia 31.

1963 - «Rapport préliminaire sur la mission de l'université de Strasbourg à Tomâs (1961)", Campagne internationale de l'Unesco pour la sauvegarde des monuments de la Nubie. Fouilles en Nubie (1959-1961), Le Caire, p.17-25.

1967 - «Les Études méroïtiques: état des questions», BSFE 50, p. 6-15. 1987 - «Trois tombes de la région de Méroé: la clôture des fouilles historiques d'el-Kadada en 1985 et 1986", Archéologie du Nil moyen 2, p. 89-119.

1997 — «From pyramids at Meroë to tumulus at el Hobagi: Imperial graves of the Late Meroitic culture (Franco-Sudanese surveys and excavations between 1983 and 1990)", Kush 17, p. 289-308.

1999 - "The division of the Meroitic Empire and the end of the pyramid building in the $4^{\text {th }}$ c. A.D.: an introduction to further excavations of imperial mounds in the Sudan ", in Recent research in Kushite History and Archaeology. Proceedings of the $8^{\text {th }}$ International Conference for Meroitic Studies (D. Welsby éd.), British Museum Occasional Paper $\mathrm{n}^{\circ}{ }^{131}$, Londres, p. 157-197. 
2004 - "El-Hobagi", in Sudan Ancient Treasures, An Exhibition of Recent Discoveries from the Sudan National Museum (D. Welsby \& J. Anderson éds.), The British Museum Press, Londres, p. 193-195.

2009 - «Une carte des derniers siècles de Méroé. Sites préchrétiens autour de l'ancienne capitale, entre Wad Ben Naga et Gabati», Kush 19, p. 59-66.

Lenoble P., Rondot V.

2003 - «À la redécouverte d'El-Hassa. Temple à Amon, palais royal et ville de l'empire méroïtique», Cripel 23, Lille, p.101-115.

Lenoble P., Sokari A.

2005 - «A Forgotten Meroitic Agglomeration in the Region of Meroe (Ne-36-O/8-H-2)», SudNub 9, p. 59-61.

Lepsius C. R. $\quad \mathbf{1 8 4 9 - 1 8 5 9}$ - Denkmäler aus Aegypten und Aethiopien, 5 vols. textes et 12 vols. planches, Berlin.

Macadam M. F. L. 1949 - The Temples of Kawa. I. The Inscriptions, Oxford, Oxford University Press.

Maillot M. $\quad 2008$ «Palais et grandes demeures du royaume de Méroé, les relais du pouvoir central», Camenulae $\mathrm{n}^{\circ}$ 2, Paris.

2013 a — «Les palais de Méroé, relais du pouvoir », Dossiers pour la science 80, Paris, p. 66-71.

2013 b — "The Palace of Muweis in the Shendi Reach: A case study", in Actes du colloque Les maisons-tours en Égyte durant la Basse Époque, les périodes ptolémaïques et romaines, Paris, p.1-16.

2014 - "The palace of Muweis in the Shendi Reach, a comparative approach", in The Fourth Cataract and Beyond, Proceedings of the $12^{\text {th }}$ International Conference for Nubian Studies, Leuven, Paris, Walpole, p. 783-795.

2015 - "The palace of Mouweis and the Early Meroitic Levels: Contribution of the Technological Analysis to the Architectural Study", à paraître.

Mainterot P. 2010 a — «es Éthiopiens et leur cité fabuleuse dans les récits classiques», in Baud M. (dir.), Méroé, un empire sur le Nil, musée du Louvre éditions, Officina Libraria, Paris-Milan, p.19-21.

2010 b - «De l'exploration des sources du Nil au voyage à Méroé", in Baud M. (dir.), Méroé, un empire sur le Nil, Musée du Louvre éditions, Officina Libraria, Paris-Milan, p. 22-27. 2011 - Aux origines de l'Égyptologie, Voyages et collections de Frédéric Cailliaud (1787-1869), Pur, Rennes.

Mallinson M.D.S

1996 - M. D. S. Mallinson, L. M. V.Smith, S. Ikram, C. Le Quesne et P. Sheehan, Road Archaeology in the Middle Nile, vol. 1, Londres. 
Maystre C. $\quad 1973$ - «Excavations at Tabo, Argo Island 1965-1968. Preliminary

Report", Kush 15, p. 193-199.

McKenzie J.S. 2007 - The Architecture of Alexandria and Egypt between 300 B.C. and 700 A.D., Londres, New Haven.

Millet N. B. 1963 - "Gébel Adda. Preliminary Report for 1963", Jarce 2, p. 147-165.

1964 - "Gébel Adda Expedition Preliminary Report», Jarce 3, p. 7-14.

1967 - «Gébel Adda. Progress Report of the Nubian Expedition

of the American Research Center in Egypt Inc. (1963)», Campagne

Internationale de l'Unesco pour la sauvegarde des monuments

de la Nubie. Fouilles en Nubie (1961-1963), Le Caire, p. 123-126.

1968 - Meroitic Nubia. Thèse de doctorat non publiée,

Ann Arbor University Microfilms.

Millet N. B., Näser C.

2011 - «Early Musawwarat» in Hommages Lenoble, Puf, Sfdas \& Ifpo (Rondot, V., Alpi, F. and Villeneuve, F. eds.), p. 317-338.

Nur S.E. 1962 - "The Circular Brick Building at Wad Ben Naga», CdE 37, p. 76.

O’Connor D. 1989 - "City and Palace in New Kingdom Egypt», Cripel 11, p. 73-87.

Paner H. $\quad 1997$ - «Khartoum-Atbara Rescue Project, Shendi-Begrawiya Section Field Project», Kush 17, p.137-155.

le Soudan

\section{Payne J.}

Petrie W.M.F.

histoire et

civilisations
Pinch G.

Pline l'Ancien

Reinold J.
2005 - "The Awlib Temple Complex: Report on the 2001 and 2003

Excavation Seasons", Gamar 3, p. 54-55.

2007 - «Excavation of the Late Kushite and Medieval settlement on Umm Muri», SudNub 9, p. 9-13.

$\mathbf{1 8 9 4}$ - Tell el-Amarna, Londres.

2004 - Egyptian Mythology: A Guide to the Gods, Goddesses,

and Traditions of Ancient Egypt, Oxford.

Histoire Naturelle. Livres VI et XIII. Texte établi et traduit par Ernout A., Les Belles Lettres, Paris, 1956.

1986 - «La nécropole néolithique d'el-Kadada au Soudan central, quelques cas de sacrifices humains», Nubische Studien (M. Krause éd.), Mayence, p. 159-169.

1991 - "Néolithique soudanais: les coutumes funéraires", in Egypt and Africa. Nubia from Prehistory to Islam (W.V. Davies éd.), Londres, p.16-29.

1994 - "Les fouilles françaises et franco-soudanaises: el-Kadada», in Nubie. Les cultures antiques du Soudan (B. Gratien et F. Le Saout éd.), Lille, p. 51-66.

1998 - «Le Néolithique de Haute Nubie. Traditions funéraires et structures sociales", BSFE n ${ }^{\circ}$ 143, Paris, p.19-40.

2000 - Archéologie au Soudan. Les civilisations de la Nubie, éditions Errance, Paris. 
2008 - La nécropole néolithique d'el-Kadada au Soudan central,

ERC, Paris.

Reisner G.A. 1910 - The Archaeological Survey of Nubia. Report for 1907-1908, 2 vols., Le Caire.

1917 - "The Barkal Temples in 1916», JEA 4, p. 213-227.

1923 - "The Meroitic Kingdom of Ethiopia. Archaeological Outline»,

Rilly C., Francigny V. JEA 9, p. 34-77.

2010 - «Excavations in Sedeinga. A New Start», SudNub 14, p. 62-68.

2011 - "The Late Meroitic Cemetery at Sedeinga. Campaign 2010", SudNub 15, p. 72-79.

Robichon C., Barguet P., Leclant J. 1954 - Karnak-Nord IV, Le Caire.

Roccati A. $\quad 1997$ - «Excavating the Palace of Natakamani at Napata: the Entrances.» Kush 17, p. 12-18.

2003 - "Napata, the destroyed city. A method for plundering", in M. Liverani éd., Arid Lands in Roman Times, Rome, p. 59-64. 2004 - "Hellenism at Napata», in T. Kendall (éd.) Nubian Studies 1998, Boston, p. 384-388.

2008 - "The Italian Archaeological Expédition to Jebel Barkal/ Napata", in Between the Cataracts. Proceedings of the $11^{\text {th }}$ Conference for Nubian Studies, Warsaw University, 27 August-2 September 2006, PAM Supplement Series 2/1, Varsovie p. 249-261.

2014 - «B 2400, A new page in Meroitic Architecture», in Ein Forscherleben zwischen den Welten. Zum 80. Geburtstag von Steffen Wenig. Der Antike Sudan-MittSAG Sonderheft (Festschrift Wenig), p. 293-298.

Roccati A., Bergamini G.

1999 - «Scavi a Napata», in St. Wenig éd., Studien zum antiken Sudan, Meroitica 15, 633-642.

Rondot V. 2005 - "El-Hassa au cœur de l'empire méroïtique», in L'Archéologie, la France et le monde. Vingt ans de recherches soutenues par le ministère des Affaires étrangères, AdpF/Maison-Neuve et Larose, p.399-401. 2006 - "Le qore Amanakhareqerem et son temple à Amon d'el-Hassa», in Kerma et Méroé, Cinq conférences d'archéologie soudanaise, Sfdas, Khartoum, p. 41-47.

Rumscheid F. 1998 - Priene: a guide to the "Pompeii of Asia Minor", Istanbul. Sauneron S. $\quad 1964$ — "Villes et légendes d'Égypte», Bifao 62, p.33-57.

Scott-Moncrief P. D.

1908 - "The ruined sites of Masawwarat es-Sufra and Naga", Proceedings of the Society of biblical Archaeology XXX, Londres. 
Sewell J. $\quad 2010$ - The formation of Roman urbanism, 338-200 B. C.: between contemporary foreign influence and Roman tradition, JRA Supplement Series 79, Portsmouth.

Shinnie M. $\quad \mathbf{1 9 5 8}$ - Linant de Bellefonds. Journal d'un voyage à Méroé dans les années 1821 et 1822, Khartoum.

1967 - Meroe. A civilization of the Sudan, Londres.

1970 - «Excavations at Meroe», MNL 5, p. 17-19.

1984 - «Excavations at Meroe (1974-1976)», Meroitica 7, p. 498-504.

Shinnie P. L., Bradley R.

1980 - The capital of Kush, I. Meroe excavations 1965-1972, Meroitica 4, Berlin.

Smith H.S. $\quad \mathbf{1 9 6 2}$ - Preliminary Reports of the Egypt Exploration Society's Nubian

Survey, Le Caire.

Smith H.S., Adam A.

1950 - «Four Ancient Sites in the Island of Meroe», $S_{N R}$ 31, p. 301-306.

Smith W.S. $\quad 1958$ - The art and architecture of Ancient Egypt, Londres, Penguin Books.

Sordi M.N. 2010 - "Gébel Barkal: New Excavation in B 2200 ", in Between the Cataracts, PAM Supplement Series 2/2, Varsovie, p. 181-187.

Spencer N. $\quad 2010-$ «Nubian architecture in an Egyptian town? Building E12.11 at Amara West», SudNub 14, p. 15-24.

le Soudan Thomas R. 2008 - "The Origin and Use of Ceramics on the Islands of Mis and Umm Muri, in the Late Meroitic to Christian Periods", SudNub 12, p. 64-73.

Török L. 1992 - «Ambulatory Kingship and Settlement History. A Study on the Contribution of Archaeology to Meroitic History", in Ch. Bonnet (éd.) Études Nubiennes, vol. I, Genève, p. 111-126.

1997 a - Meroe City, an Ancient African Capital. John Garstang's excavations in the Sudan, 2 vols., Londres.

$\mathbf{1 9 9 7} \mathbf{b}$ - The Kingdom of Kush: Handbook of the Napatan-Meroitic Civilization, La Haye.

2002 - The Image of the Ordered World in Ancient Nubian Art. The Construction of the Kushite Mind, 800 BC-300 AD, Probleme der Ägyptologie 18, Leiden- Boston-Köln.

2009 - Between Two Worlds. The frontier region between Ancient Nubia and Egypt 3700 BC-500 AD, Pdت̈ 29, Leyde-Boston, Brill.

2010 - «La royauté méroïtique», in Baud M. (dir.), Méroé, un empire sur le Nil, musée du Louvre éditions, Officina Libraria, Paris-Milan, p. $165-172$.

Traunecker C. 2010 - «La chapelle d'Osiris "seigneur de l'éternité-neheh" à Karnak», in Le culte d'Osiris au premier millénaire av. J.-C., Actes de la table ronde internationale tenue à Lyon, Maison de l'Orient et de la Méditerranée, les 8 et 9 juillet 2005, Le Caire, p.155-195. 
Trigger B. G. 1967 - The Late Nubian Settlement at Arminna West. New Haven, Peabody Museum.

1976 - Nubia under the Pharaohs, New Haven.

Uphill E. $\quad \mathbf{1 9 7 2}$ - "The concept of the Egyptian palace as a "ruling machine" ", in Ucko. P. J., Tringham. R., and Dimbleby. G.W. (éds.), Man. Settlement and Urbanism, Londres, Duckworth.

Vercoutter J. $\quad 1962$ — «Un palais des “candaces” contemporain d'Auguste.

Fouilles à Wad ben Naqa (1958-1960)», Syria 39, p. 263-299.

Vercoutter J., Adams W.Y.,

1961 - Why excavate in Sudanese Nubia, Sudan Antiquities Service.

Verwers G.J. $\quad 1962$ - "The Survey from Faras to Gezira Dabarosa», Kush 10, p. 19-33.

Vitruve De l'Architecture. Livre iv. Texte établi et traduit par Gros P.,

Les Belles Lettres, Paris, 1992.

Vlach F.

1984 - "Meroitisch-hellenistische Plastik aus den sogenannten königlicher Bädern. Ein Arbeitsbericht", Meroitica 7, p. 573-576.

Vrtal V. 2014 a - "The palace of Queen Amanishakhéto", in Onderka P., Vrtal V.et al. (éds.) Nubia, A land on the Crossroads of Cultures, Wad Ben Naga 2014, Národní Museum, p. 164-177.

2014 b — "The Circular Building (WBN 50)", in Onderka P., Vrtal V.et al. (éds.) Nubia, A land on the Crossroads of Cultures, Wad Ben Naga 2014, Národní Museum, p. 152-163.

Welsby D.A. $\quad \mathbf{1 9 9 6}$ - The Kingdom of Kush. The Napatan and Meroitic Empires, Londres.

2000 - "The Kawa Excavation Project», SudNub 4, p. 5-10.

2001 a - Life on the Desert Edge. Seven Thousand Years of Settlement in the Northern Dongola Reach, 2 vols., Londres.

$2001 \mathbf{b}$ - "Excavations within the Pharaonic and Kushite

Site at Kawa and its Hinterland, 2000-2001», SudNub 5, p. 64-70.

2002 - «Kushite buildings at Kawa», BMSAES 1, 26-39.

2003 - Survey above the Fourth Nile Cataract, Londres.

2004 - "Kawa», in D. A. Welsby et J. R. Anderson (éds.) Sudan

Ancient Treasures, Londres, p. 148-157.

2009 - «Houses and Pyramids at Kawa, excavations 2008-9",

SudNub 13, p. 72-77.

2010 - "Excavations at Kawa, 2009-10», SudNub 14, p. 48-55.

Wenig S. $\quad 1992$ - «ommentar zu Török: Ambulatory Kingship and Settlement

History. A Study on the Contribution of Archaeology to Meroitic History", in Étnub I, p. 137-140.

Wenig S., Wolf P. 1998 a — «Feldarbeiten des Seminars für Sudan-Archäologie und ägyptologie der Humboldt-Universität in Musawwarat es Sufra. Erste Hauptkampagne (1995-1996)", MittSag 8, p. 24-37. 
le Soudan

\section{8}

histoire et civilisations
$1998 \mathbf{b}$ - «Feldarbeiten des Seminars für Sudan-Archäologie und ägyptologie der Humboldt-Universität in Musawwarat es Sufra. Zweite Hauptkampagne (1996)", MittSag 8, p. 38-49.

1999 - «Feldarbeiten des Seminars für Sudan-Archäologie und ägyptologie der Humboldt-Universität in Musawwarat es Sufra. Dritte Hauptkampagne (1997)", MittSag 9, p. 24-43. 2000 - «Feldarbeiten des Seminars für Sudan-Archäologie und ägyptologie der Humboldt-Universität in Musawwarat es Sufra. Vierte Hauptkampagne (1998)», MittSag 10, p. 28-48.

Whitehead G. O. 1928 - «Nagaa and Musawwarat», $S_{N R}$ 9, p. 59-67.

Wildung D. $\quad 1997$ - (dir.) Soudan. Royaumes sur le Nil, institut du Monde arabe, Paris. 1998 - «Naga Project (Sudan) —Egyptian Museum Berlin Preliminary Report 1995-1996, Seasons 1 and 2", ANM 8, p. 183-190. 1999 - Naga, die Stadt in der Steppe. Grabungen Des Ägyptischen Museums im Sudan, Berlin.

Wildung D., Kroeper K.

2006 - Naga. Royal City of Ancient Sudan, Berlin.

2011 - Königsstadt Naga: Grabungen in der Wüste des Sudan = Naga-

Royal City: excavations in the desert of the Sudan, Sonderausstellung München, Staatliches Museum Ägyptischer Kunst, Berlin, Munich. Wilson K.L. $\quad \mathbf{1 9 8 2}$ - Cities of the Delta II: Mendes. Preliminary Report on the 1979 and 1980 Seasons, ArCe Reports 5, Malibu.

Wolf P.

1997 - «Recent Fieldwork at Musawwarat es-Sufra», SudNub 1, p. 20-29.

1998 - «Bericht über die Konservatorischen Arbeiten

in Musawwarat es Sufra. Zweite Hauptkampagne, 1.2.-1.4.1996",

MittSag 8, p. 10-12.

2001 a - «Die Untersuchungen zur Baugeschichte an der Nordseite der Zentralterrasse», MittSag 11, p. 16-23.

2001 b - «Die Höhle des Löwen. Zur Deutung der Großen

Anlage von Musawwarat es Sufra", in Arnst, C.-B., Hafemann, I. \&

Lohwasser A. (éds.), Begegnungen, Antike Kulturen im Niltal, Festgabe für Erika Endesfelder, Karl-Heinz Priese, Walter Friedrich Reineke, Steffen Wenig, Leipzig, p. 473-508.

2002 - "Ausgrabungen in Hamadab bei Meroe», MittSag 13, p. 92-111. $2004 a$ - «Steps Toward the Interpretation of the Great Enclosure of Musawwarat es-Sufra», in T. Kendall (éd.) Nubian Studies 1998, Boston, p. 436-445.

2004 b - «The SARS Anglo-German Expédition at the Fourth Cataract of the Nile: the 2003/04 Season", SudNub 8, p.17-26.

2004 c - «Hamadab—das Hauptquartier des Akinidad?», MittSag 15, Berlin, p. 83-97. 
2004d - «Fieldwork of the Humboldt University of Berlin at Musawwarat es Sufra 1993-2000", Meroitica 21, p. 47-101. 2006 - «Hamadab — Fouille d'un site urbain méroïtique, campagnes 2001-2003", ANM 10, p. 257-264.

Wolf S., Hof C., Onasch H.-U.

2003 - «Investigations in the so-called Royal Baths at Meroë in 1999.

À Preliminary Report", Kush 18, p. 71-87.

2008 - «Investigations in the so-called Royal Baths at Meroë in 2000, 2004 and 2005", Kush 19, p. 101-116.

Wolf S., Wolf P., Onasch H.-U., Hof C., Nowotnick U. 2008 - «Meroë und Hamadab_Zwei Städte im Mittleren Niltal in den Jahrhunderten um die Zeitenwende. Bericht über die Arbeiten zwischen 1999 und 2007", Archäologischer Anzeiger 2008/2, Berlin, p. $157-230$.

2009 - «Meroë und Hamadab-Stadtstrukturen und Lebensformen im afrikanischen Reich von Kusch. Die Arbeiten der Saison 2008 und 2009, Archäologischer Anzeiger 2009/2, Berlin, p. 215-262.

Woolley, C. L. 1911 - Karanog. The Town, Eckley B. Coxe Junior Expedition to Nubia, vol. 5, Philadelphie.

Woolley C. L., Randall-Maciver D.

1910 - Karanog. The Romano-Nubian Cemetery. Eckley B. Coxe Junior Expedition to Nubia, vol. 3 et 4, Philadelphie.

Yellin J. 2014 - "The Kushite Nature of Early Meroitic Mortuary Religion: A Pragmatic Approach to Osirian Beliefs", in Ein Forscherleben zwischen den Welten. Zum 80. Geburtstag von Steffen Wenig. Der Antike Sudan-MittSAG Sonderheft (Festschrift Wenig), p. 395-404.

Yoyotte J. $\quad 2006$ - «Le Portus Magnus d'Alexandrie» (avec la collaboration de F. Goddio), in Trésors engloutis d'Égypte, Seuil, Paris, Milan. 2010 - "Osiris dans la région d'Alexandrie», in Le culte d'Osiris au premier millénaire av.J.-C., Actes de la table ronde internationale tenue à Lyon, Maison de l'Orient et de la Méditerranée, les 8 et 9 juillet 2005, Le Caire, p. 33-39.

Zurawski B. 2002 - «Survey and Excavations Between Old Dongola and ez-Zuma», SudNub 6, p. 73-85. 